\title{
QK60I
.P82
}

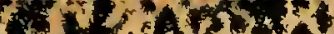

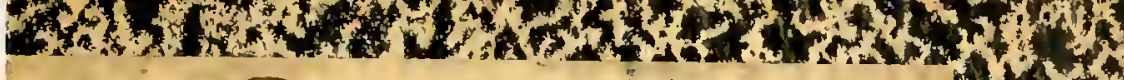

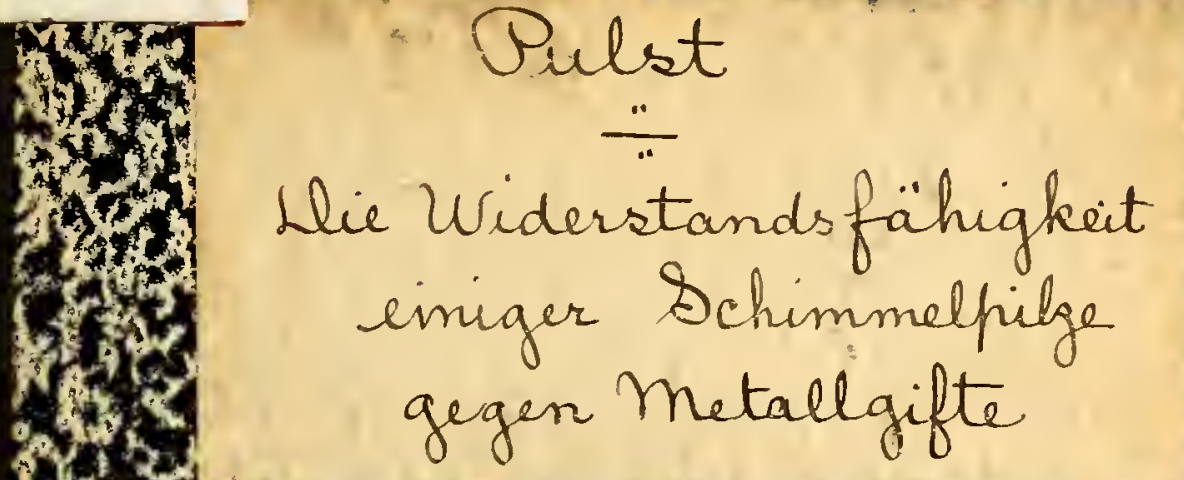

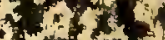

ind

$(1)+2$

t 5

a.

$+8$

$-1$

$1+3+1$

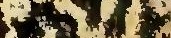

D. 1.3

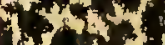

$20,5>2$

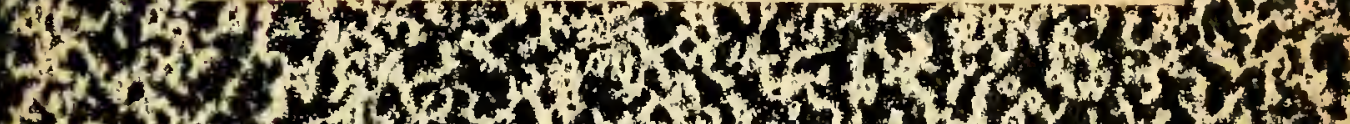

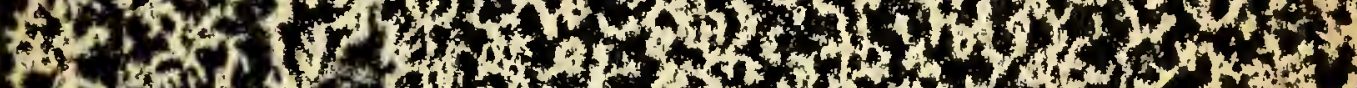

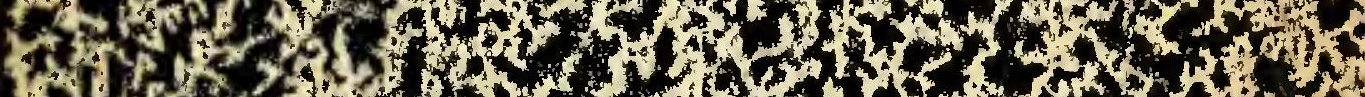

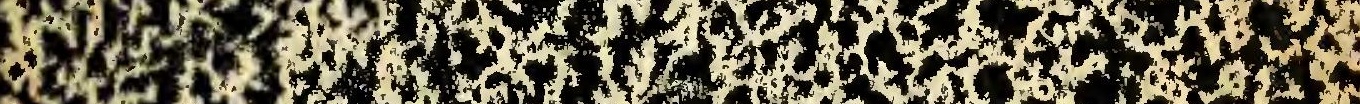

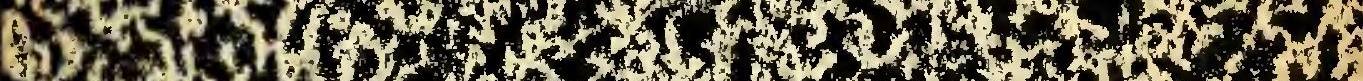

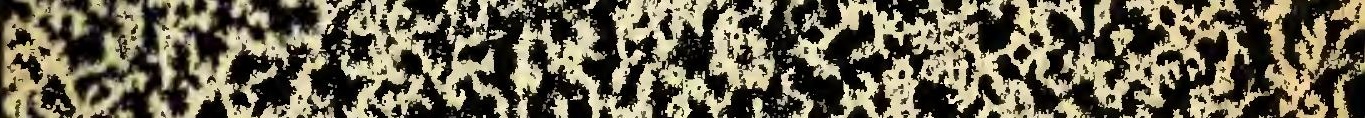

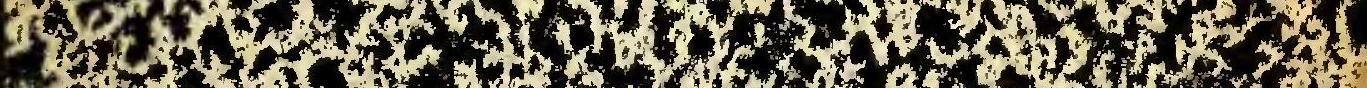

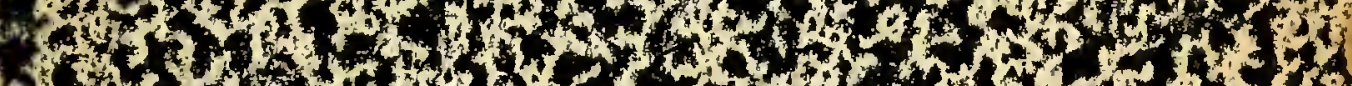

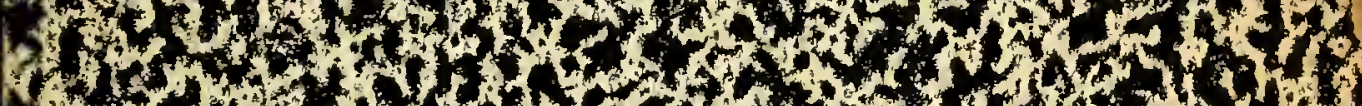

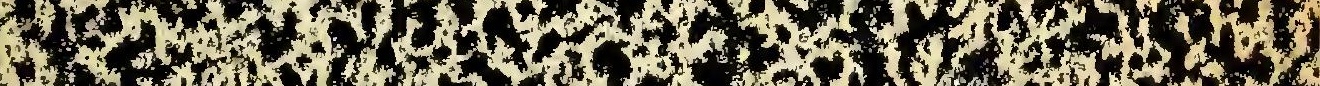

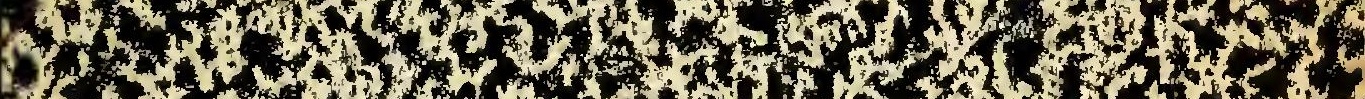

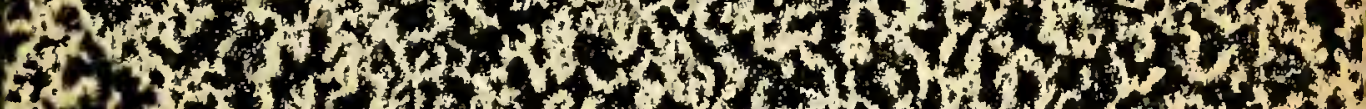

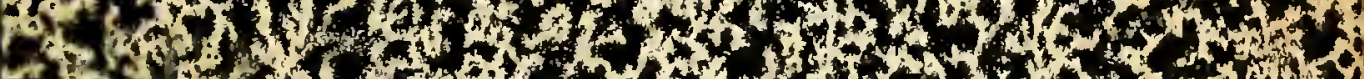

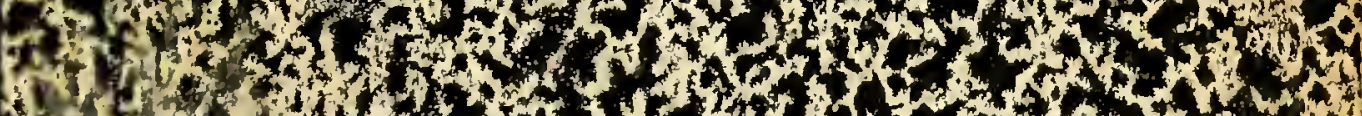

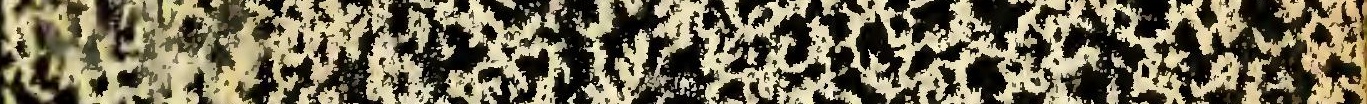

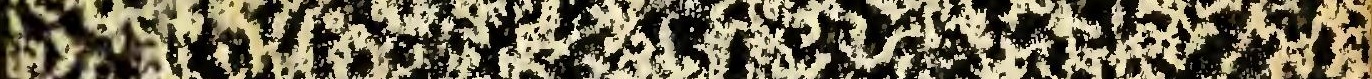

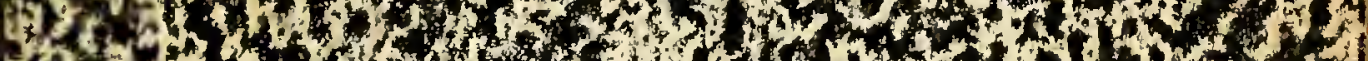
S6)

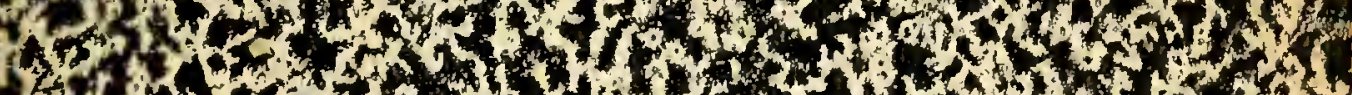

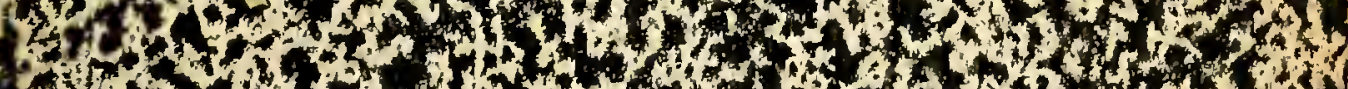

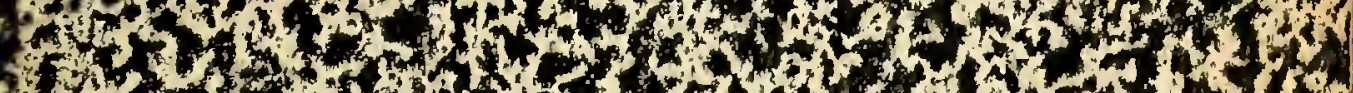
P.

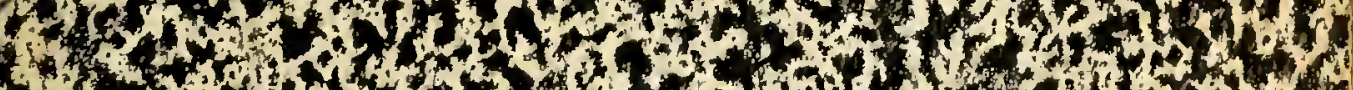

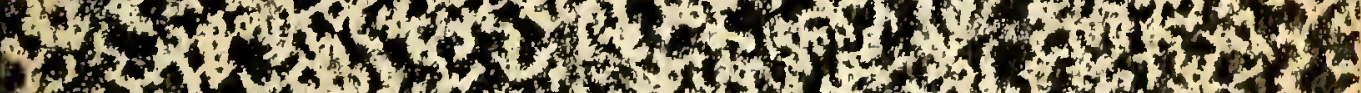

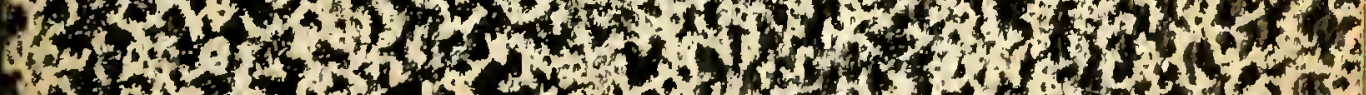

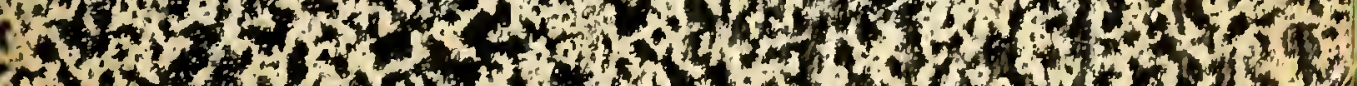
Q 


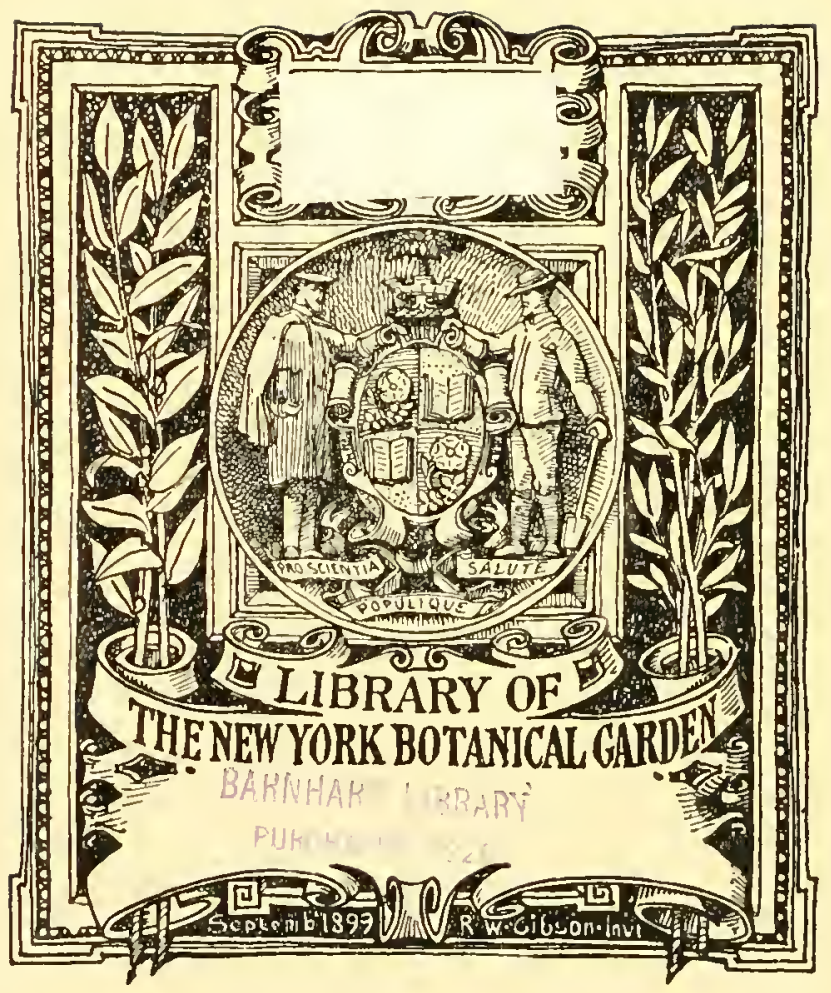






\section{Die Widerstandsfähigkeit}

einiger Schimmelpilze g'egen Netallgifte

INAUGURAL - DISSERTATION

ZUR

ERLANGUNG DER DOCTORWÜRDE

DEH

HOHEN PHILOSOPHISCHEN FACULTÄT

DEI:

UNIVERSITÄTT LEIPZIG

VORGELEGT VON

CARL PUIST

ATS BERTIN

Sit 2 Textfiguren

Leipzig

Ge brüd er B orntraeger

1902 



\section{Die Widerstandsfäligkeit}

\section{eimiger Schinmelpilzze gegen Metallgiitte}

\section{INAUGURAL - DISSERTATION}

ZUR

\section{ERLANGUNG DER DOCTORWÜRDE}

DER

HOHEN PHILOSOPHISCHEN FACUITAT

DEK

UNIVERSITÄT LEIPZIG

VORGELEFT VON

\section{C'A IR L PUIAST}

AUS BERLIN

Mit 2 Textfiguren

LIBRART

YEW YOR:

(1) 1 A $\cap \mathrm{A}^{\prime}$

-IEA

\section{Leipzig}

Gebrüder Borntraeger 



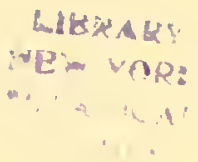

\section{Vita.}

Geboren am 14. Juli 1868 zu Berlin als Soln des Apothekenbesitzers Carl Pulst ebendaselbst, erhielt ich, Carl Pulst, evangelischen Glaubens, meine Gymuasialbildung auf dem dortigen Collège royal français und dem Königlichen Gymnasium zu Freienwalde a. O., welches ich nach $2{ }^{1}{ }_{2}$ jälnigem Besuche der Prima rerliess, um mich dem pharmacentischen Berufe zu widmen. Nach der praktischen Ausbildung bezog ich nacheinander dic Universitïten Berlin und Leipzig, an welcher letzteren ich in Mai 1898 die Statatsprüfung als Apotheker bestand und mich in der Folge besonders botanisch-physiologischen Studien widmete.

Während meiner Studienzeit in Berlin besnchte ich die Torlesungen und Practica der Herren Professoren Engler, Fischer, Warburg und Thoms - in Leipzig diejenigen der Herren Prolessoren Pfeffer, Wislicenus, Wiedemann, Wiener, B̈̈hm und Beckmann.

Allen meinen hochverehrten Lehrern spreche ich im Alıschlusse meiner Universitätsstudien meinen anfrichtigen Daulians. 

Es ist lange bekannt, dass manche Organismen sowohl des 'Thicr- wie des Pflanzenreiches regen Stoffe organischer nnd anorganischer Natur, welche wir wegen der tödtlichen Wirkung verLältnissmässig kleiner Mengen schlechthin als Gifte bezeichnen, sehr widerstandsfähig sind ${ }^{1}$ ).

Diese Thatsache ist allerdings gemäss den Angaben der alten Literatur anch für die höher organisirten Vertreter des Pflanzenreiches in mehr oder minder holem Grade festgestellt worden ${ }^{2}$ ), sie tritt aber in höherem Maasse bei den niederen Pflanzen, den Bakterien $^{3}$ ) und ganz besouders bei den Schimmelpilzen' ${ }^{t}$ in die Erscheinung.

1) Loew, Giftwirkungran 1 , 221 und 32 .

2) Nobbe. Fanenkume 1s76, physinl. Th. 1. 273; 11 aberland, Landw. Centralhl.

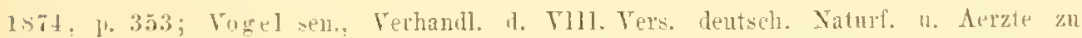

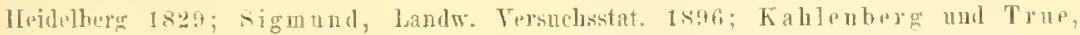

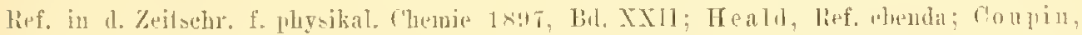

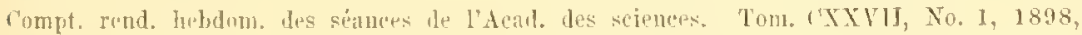
p. 400 .

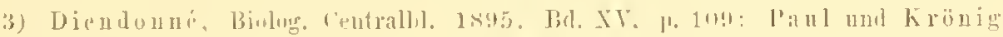

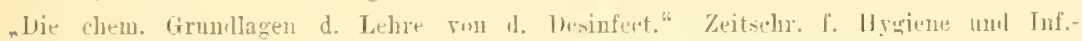

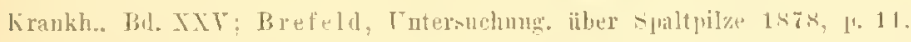

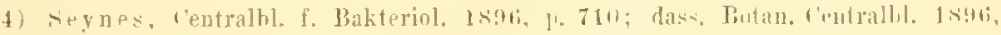

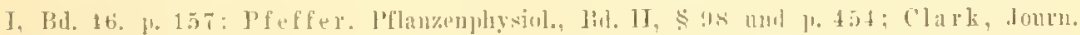

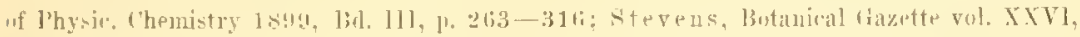
1898 , II, p. 400); Trabut, Bullet. de la Suc, botan. He Frnee 1895. T. 12, J. 33 ; Gosio, Ber. d. Deutsch. chem. Ciesellich. 1897, 11. 11121. 
Die Wirkung, welche die im Nährboden gebotenen Gifte auf den Organismus ausïben, wirl sich naturgemäss - wie das besonders in den citirten Arbeiten von Paul und Krönig Berücksichtigung findet - in zweierlei WVeise bemerkbar machen: das Gift des Substrates wird entweder die Eutwickelung des Pilzes hemmen heziehungsweise verhindern oder aber die Entwickelungsfähigkeit desselben sänzlich vernichten, $d$. h. eine tödtliche Wirkung ansiiben.

Anlehnend an alle diese Erfahrungen, die in der älteren und neueren Literatur ihreu Ausdruck finden, und diejenigen über die Anfnahme der Metalle, welche iu dem Cilpitel über die entbehrlichen Aschenbestandtheile von Pfeffer.') zusammengestellt sind, hatte ich es mir zur Aufgabe gemacht, einige Versuche nit den vier. Schimmelpilzen, Hucor mucerlo. Asperyillus niger, Botrytis cinerea und I'enicillium ylaucum, anzustellen, un ihre Resistenz gegen einige Metallgifte festzustellen und miteiuander zu vergleichen. Diese Feststellung der Resistenz sollte sich lediglich auf die Möglichkeit einer Fntwickehung der genanuten Pilze auf dem das jeweilige Metallgift enthaltenden Nührboden erstreclien ohne wesentliche Bericksichtigung der direct tödtichen Wirkngen der Netallgifte. Es komuten somit nur diejenigen Concentrationen als Grenzconcentrationen in Frage kommen, welche die Entwickelung der Pilze zn verhindern geeignet sind, ohne dieselbe durch Vernichtung des Lebens unbedingt ummöglich zu machen.

IVie aber einem animalischen Organismus erfahruugsgemäss die andanernde Gewölnumg an denselben, unter normalen Bedinguugen schädlichen Stoff eine grössere Resistenz verleiht, so musste bei der Feststelluug der Wachsthumsgrenzen obiger vier Pilze auch dieser Factor der Accommodation berücksichtigt werden.

Eine solche dccommodation aber kounte sowoln von dem Versuchsobject selbst durch zeitlich lange Berihhrung mit dem Giftstoff, solange dieser nicht tödtlich wirkte, erreicht werden, ats auch auf einer stufenweisen Zunahme von Generation zn Generation beruhen. lnmerhin war es fiu das Ziel meiner Arbeit nothwendig, vorerst fiu das jeweilige Metallyift die Grenzconcentration für die Entwickelung der Sporen eines in keiner Weise accommodirten Pilzes, also ciner giftereien Kultur, zu bestimmen, un damn in entsprechenden Parallelversuchen mit den Sporen eines ein oder

1) I'feffer, I'flanzemphysiol. \心!t 
mehrere Generationen hiudurch an den Giltstoft gewöhnten Pilzes zu ermitteln, ob die Resistenz gegenüber dem hemmenden Medium sich dadurch rergrössert hatte, und welcher Art diese Aupassung seitens des Pilzes ist.

Wem aber dies der Fall und damit die entwickelungshemmende Eigenschaft der Metallsalze je mach dem Grade der Acconmodation des Pilzes eine bedingte ist, so kann einerseits die Frage entsteheu, ob diese Anpassung des Pilzes eine fiir jedes einzelne der gewählten Metallsalze specielle ist'), oder ob die Anpassung desselben an das eine Gift ihm anch eine erhöhte Resisten\% einem anderen gegenüber verleilit. Andererseits aber musste, falls die Erwerbung grösserer Resistenz durch allmähliche Aupassumg largethan war, die Frage nach der Daner dieser Eigenschaft anfgeworten werden; erwies sie sich als eine voribergehende oder war sie zu einer bleibenden geworden. sodass man geneigt sein könte, ron einer Vererbung zu sprechen?

Diese Punkte umfassen somit den Hauptheil meiner Arbeiten: welchen ich schliesslich noch einige Versuche anschloss, die auf das Kiel losstenern, einen Eimblick in die Ursache der verluältnissmïssig grossen Resistenz eines Penicillium ylumenn gegenüber diesen Metallgiften, insonderheit deu Kupfer, zu gewinnen.

\section{Methodisches.}

Meine Untersuchungen iiber das Wachsthum der obigen vicr Schinmelpilze erstreckten sich auf folgende Metallsalze:

1. $\mathrm{CuSO}_{1}$,

$$
\mathrm{Na}_{2} \mathrm{Cu}\left(\mathrm{C}_{1} \mathrm{O}_{i} \mathrm{H}_{2}\right) \text { als Parallelversuch! }
$$

2. $\mathrm{ZnSO}_{\frac{1}{2}}$

3. $\mathrm{NiSO}_{4}$,

denen ich bei weiteren Versuchen mit Penicillium ylfmemm noch folgende acht Salze anschloss:

$\begin{array}{ll}\mathrm{MnSO}_{4} & \mathrm{Tl}_{2} \mathrm{SO}_{4} \\ \mathrm{Fe}_{2}\left(\mathrm{SO}_{1}\right)_{;} & \mathrm{Pb}\left(\mathrm{NO}_{3}\right)_{2} \\ \mathrm{CdSO}_{1} & \mathrm{HgCy}_{2} \\ \mathrm{CoSO}_{4} & \mathrm{HgCl}\end{array}$

Wie ersichtlich. wählte ich der Eisheitlichkeit wegen in allgemeinen die schwefelsamen Verbindungen der Metalle. Die

1) Pfeffer. Pflanzenphysinlngip, I. Anfl., Bd. II, š 98. 
weinsaure Verbindung des Kupfers, welche als Complexverbindung nit weinsaurem Natrim in weinsaurer Lösung verwendet wurle, wiilhte ich als Parallelversuch zur Wirkung des Kupfers als solchem; ebenso liessen chemisch-physikalische Gründe die Wahl des Quecksilbercyanides neben dem Chloride erwünscht erscheinen.

Dass das Blei nicht in seiner schwefelsauren Verbindung, sondern als Nitrat zur Verwendung kam, hat in der nahezu völligen Unlöslichlkeit der ersteren seinen natiirlichen Grund.

Bei der Anordnung meiner Versuche standen mir nun zwei Wege offen: Die mikroskopische Beobachtung, wie sie Clark und Stevens ${ }^{1}$ ) wählten, und die makroskopische. Da es aber in dem ersten Theile meiner Versuche nur darauf ankam, die Grenzconcentrationen für die Entwickelung auf dem betreffenden Metallgift, alsu die Wachsthumsgrenzen ohne eingehende Berïcksichtigung der Todesgrenzen festzustellen, so geniigte einual die makroskopische Methode; für den Hauptzweck derselben aber, für die Frledigung der Accommodationsfrage, war sie geboten. Denn zum Beweise der Anpassungsfähigkeit war es in der Hauptsache nöthig, die Sporen der auf solehen Gift-Nährböden kultivirten Pilze zn verwenden; mithin musste bei den jeweiligen Versuchen die Fructificationsperiode stets erreicht werden. Mit Berücksichtigung dieserNothwendigkeit wurden somit meine gesammten Versuche makroskopisch in Flaschenliulturen angestellt.

\section{Herstellung der Kulturen.}

Bei der Herstellung der die Metallsalze enthaltenden Nährlösungen kam es naturgemäss darauf an, vergleichbare Concentrationen zu schaffen. Die völlige Identitït des Nährstoff'gehaltes aber vorausgesetzt, kounten solche analogen Concentrationen mach chemisch-physikalischen Gesetzen nicht durch Lösungen von gleichem Gehalt an Gewichtsprocenten, sondern nur durch äquimolekulare Lösungen erreicht werden.

Allerdings ist, wenn durch diese Methode eine correcte Vergleichung der entwickelungshemmenden Wirkung der Metallsalze als Gifte auch ermöglicht wird, ler Factor des osmotischen Einflusses nicht berïcksiclitigt; jeduch ist derselbe bei den schwachen Concentrationen der Lösmngen, welehe zur Feststellung der Ent-

1) sieht p. 1. 
wickelungsgrenzen gewöhnlicher Pilzsporen zunïchst in der Melırzahl in Frage kamen, völlig ohue Belang. Bei stärkeren Concentrationen wird der osmotische Druck allerdings die Entwickelung auf der Giftlösung zwar nicht relativ im Sinne des Giftes, so doch zeitlich beeinflussen. Im späteren Verlaufe meiner Arbeiten habe ich daher an unbedingt erforderlicher Stelle durch einen entsprecheuden Zusatz eimes indifferenten Stoffes bei geringeren Giftconcentrationen diesem retardireuden Einflusse Rechnung getragen.

Da ich nun wegen der bis zur Fructificationsperiode gehenden Entwickelung der Pilze naturgemäss mit Nährlösungen arbeiten musste, so möchte ich gleich an dieser Stelle bemerken, dass in meiner Darlegung unter dem Ausdruck "Kupfer-, Nickelsulfatlösung" u. s.f. insonderheit stets eine Nährlösung von dem entsprechend angegebenen Gehalt an Metallgift verstauden ist.

\section{Nährlösung.}

Bei der Herstellung der Nährlösung war es neben den oben erwähnten Forderungen für die Erledigung der gestellten Fragen unbediugt von Werth, den zur Verwendung kommenden Pilzen möghichst günstige Ernährungsbediugungen zu bieten; andererseits aber musste Einheitlichkeit und Gleichheit hinsichtlich des Nährmediums, der Temperatur und des Lichtes herrschen. In Beriicksichtigung dieser Punkte und der chemischen Forderungen wählte ich eine Nährlösung von folgender Zusammensetzung, welche somit bei allen meinen Versuchen zur Verwendung lian und fiir sämmtliche Resultate maassgebend ist:

\begin{tabular}{|c|c|c|}
\hline Rohrzucker . . & & 40,0 \\
\hline Pepton . & & 5,0 \\
\hline Monokaliumphosphat & $\cdot$ & 1,035 \\
\hline Kaliumnitrat . . & - & 0,13 \\
\hline Magnesiumsulfat & & 0,16 \\
\hline
\end{tabular}

Diese Salze waren in soviel destillirtem Wasser gelöst, dass die Gesammtmenge $1000 \mathrm{ccm}$ betrug.

Ich möchte gleich hier erwähnen, dass ich diese Nährlösung aus praktischen Gründen stets in doppelter Stärke herstellte, d. h. so, dass in $1000 \mathrm{ccm}$ die einzelnen Stoffe (Zucker, Pepton und Mineralsalze) in der doppelten Monge, als oben angegeben ist, gelist wurden, sodass beim Gebrauch stets das gleiche Quantun destillirten Wasser's hinzugefiigt werden musste. 
Diese Terdoppelung des Gehaltes an Nährstoffen geschab deswegen, weil es vortheilhafter, oft sogar aus chemischen Rücksichten merlisslich war, das betreffende Metallgift für sich allein unter Frwärmen in destillirtem IVasser zu lösen und diese Lösung nach dem Erkalten mit der Nährlïsung zu vereinigen.

Die concentrirte Nährlisung wurle in sterilisirtem /ustande vorräthig gehalten.

\section{Die Metallgift enthaltenden Nährlösmgen.}

Zu sämmtlichen Versuchen wählte ich Erlenme yer'sche KochHaschen von etwa 195 ccm Inhalt. Diese wurden vor dem jedesmaligen Gebrauche mit Salzsinue gut gereinigt, 1 m etwa an der inneren Glaswandmug anhaftende, rom vorhergehenden Versucho zuriickgebliebene Spuren von Metalloxyrlen völlig zu entfernen, und lamn mit destillirtem IVasser sorgfültig nachgespült; dic so gereingten Gefässe wurden endlich mit gut schliessenden Wattestopfen versehen und darauf bei $100^{\circ} \mathrm{C}$. sterilisint.

Bej der Anstellung der Versuche wuclen nun der Controlle wegen stets mindestens je zwei Parallelkultureu angesetzt, und zwa wuden diese sämmtlich su hergestellt, lass jede der heilen Flaschen mit je $20 \mathrm{ccm}$ Metallgift enthaltender Nährflüssigkeit beschickt wurde. Zur Herstellung derselben wrde die dieser GesamutHüssiglieitsmenge vor $40 \mathrm{ccm}$ entsprechende Menge des krystallisirten Metallsalzes in Grammmolekülen abgrewogen, für sich in destillirtem $\mathrm{W}$ assel - eventuell unter Erwärmen - gelöst, diese Lösung im Messcylinder durch /usatz von destillirtem IV asser auf $20 \mathrm{ccm}$ anfgefiillt und uach dem Erkalten unit 20 con der concentrinten Nährösung vermischt. Diese Metallgift entlaltende Nihrlösung wurde nummehr auf zwei sterilisirte Flaschen gleichmässig zu je $20 \mathrm{ccm}$ vertheilt, und dieselben mit einer entsprechenden Marke an der Aussenwand rersehen, welche die Standhöhe zur Zeit der. Impfung augab.

Diese Art der Herstellung der Gesammtlösung für je zwei Parallelkulturen wihlte ich einmal aus praktischen Riicksichten, dann aber vor allem: um in diesen Parallelkulturen in jeder Bezielıung völlig gleiche Bedingungen zu erzielen.

Da beim Erwärnen der Metallgift enthalteuden Nährlösungen durch chemische Einwirkwngen theilweise Fitllungen auftraten, so nakm ich das sterilisiren erforderlichen Filles getreunt vor, indem 
die $20 \mathrm{ccm}$ der wässerigen Metallsalzlösung für sich sterilisirt und nach dem Erkalten mit der entsprechenden Vorsicht mit den $21) \mathrm{ccm}$ der sterilen, concentrirten Nährlösmng vermischt wurden.

Die bei den stark rerdünten Lösungen des Quecksilberchlorides denuoch in Folge der Nährsalze auftretender Fällungen konnte ich durch ganz geringe Zusätze ron selı verdiunter Salzsäure wieder in Lösung bringen.

\section{Impfung.}

Die in der beschriebenen Teise hergestellten Nälnmedien wurden nun mittelst einer sterilen Platinuadel so geimpft, dass mit einer Platinöse eine grössere Menge von Sporen ïbertragen wurde. Da beiu Vergleichen die Menge der jedesmal geimptiten Sporen bei lediglich makroskopischer Beobachtung insoweit einen Einfluss anf die Beurtheilung der Entwickelung hat, als heispielsweise 100 Sporen sich - ceteris paribus - schueller zu einer Decke entwickeln werden als etwa 10 derselben, so hielt ich es für angezeigt. stets eine grössere Menge zu übertragen. Wenn dadurch auch ebensowenig eine viollige Gleichheit erreicht werden kounte, so wurde der relative Unterschied in der Menge bei einer grösseren Auzahl ron Sporew denuorl erheblich herabgemindert und damit eine rergleichende Beurtheilung möglich.

Die so geimpften Kulturen wurden alsdann der Einheitlichkeit wegen ansnahmslos dauernd im Dunkelschrank in einen Zimmer mit coustanten Temperaturen ${ }^{1}$ ) bei einer Temperatur rou $26^{11}$ bis $28^{\circ} \mathrm{C}$. gehalten.

\section{Erklärung der Tabellen.}

Nach dieser Beschreibung meiner Tersuchsanorlnungen möchte ich zur leichteren Uebersicht ein Beispiel des vou mir für sïnmtliche Tabelleu angewendeten Schemas geben (siehe folg. Seite).

In dieser Tabelle siebt die Terticalreihe I den abgerundeten Gehalt in Procenten und zwar a) an reinem Metalle, b) an krystallisirtem Salze an; in der Verticalreihe II bezeichnet die /ahl jeweilig die Anzahl der Liter, in welchen ein tirammmolekiil des Salzes gelöst ist. sodass im Verlaufe der Arbeit der Kürze halber

1) Pfeffer, Ber. d. Deutsch. botan. Gesellsch. 1895, 1. 44. 


\section{Penicitlium glancum.}

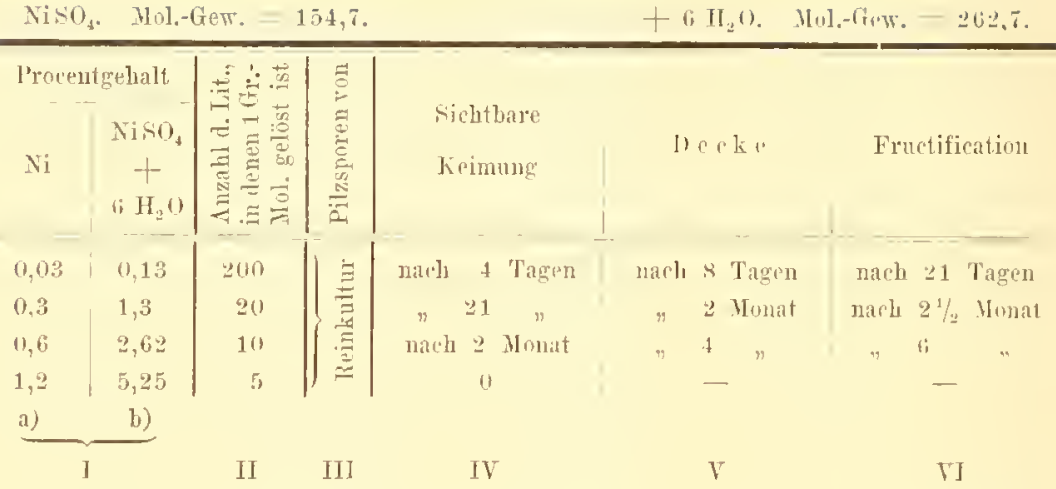

mit dem Ausdruck ..Concentration von 5 etc. Litern" stets eine Nährlösung gemeint ist, welche in 5 etc. Litern ein Grammmolekii] des Salzes gelöst enthält. Die Verticalreihe III giebt an, woher die zur Impfung gelangten Sproren stammten, $d, h$, ob der Pilz, dessen Sporen verwendet wurden, auf einer Reinkultur oder auf einer bereits Metallgift enthaltenden Nïhrfliissigkeit, deren Concentration dann hier in Litern angegeben ist, kultivirt war. Die Daten der drei letzten Verticalreihen bedürfen einer weiteren Erklärmug nur insoweit, als dieselben als Durchschnittswerthe aufgefasst werden müssen; eine 0 bezeichnet hier stets, dass eine Entwickelung iiberhaupt nicht mehr stattfand.

Nach diesen Erläutermugen ïber die Art und Anordnung meiner Versuche bin ich nun in der Lage, zur Behandlung derselben selbst überzugehen und an der Hand ler aufgestellten Tabellen die Resultate meiner Beobachtungen in Beantwortung der eingangs anfgestellten Fragen mitzutheilen.

\section{Welches sind die Concentrationsgrenzen der in Frage kommenden Metallsalze für die Entwickelung der vier Schimmelpilze?}

Bei solchen Versuchen, wie die vorliegenden, darf man nicht vergessen, dass bei einer Bestimmung der Wachsthumsgrenzen die Resultate nm Anmäherungswerthe sein können. Der natürliche Grund liegt darin, dass man in der physiolngischen Botanik nicht, wie etwa in der Chemie oder Physik, nit genan berechenbaren und bestimmbaren Factoren arbeitet, sondern es viehnehr mit einem 
lebenden Organismus zu thun liat, dessen Lebensfunctionen von vielen Zufälligkeiten abhängig sind. Auch wenn, wie im rorliegenden Falle, nach Möglichkeit die grösste Sorgfalt anf die Herstellung gleicher inusserer Lebensbedingungen rerwendet worden ist, so werden dennoch grössere oder kleinere Schwankungen in der Entwickelung und dem Wachsthum des Pilzes unausbleiblich sein; ein Umstand, welcher u. a. schon in der oben erwähnten Art der Impfung eine Erklïrung findet.

Ans eben diesen Gründen kömen anch die von mil gefundenen Werthe für die Wachsthumsgrenzen in gewissem Sinne nur für diese bestimmten vorliegenden Verhältnisse Anspruch auf Richtigkeit machen; sie können also in gewissem Sinne uur bedingte Resultate darstellen. Denn jede Veränderung der änsseren Bedingungen - der Nährstoffe, der Temperatur oder dergl. - könnten geeignet sein, zu Abweichungen Veranlassung zu geben.

Ferner ist es bekannt, dass die Sporen der Bakterien ${ }^{1}$ ) in der Regel resistenter gegen Gifte oder sonstige schädliche Einflüsse, wie ultra-maximale oder -minimale Temperaturen und dergl., sind. Somit werden, abgesehen ron jenen äusseren Bedingungen. die Resultate nocls ron dem augenblicklichen Zustande des Organismus, der diesen Einwirkungen ausgesetzt ist, abhängig sein; es wird also darauf ankommen, ob der Pilz sich in der Vegetationsruhe, in Zustande der Keimentwickelung, also des Erwachens aus jener, oder der Weiterentwickelung, also les Wachsthums, befindet. In diesem Simne habe ich allerdings auch einige Versuche mit den Hyphen der Pilze nebenher angestellt; immerhin aber kam es mir darauf an, die Wachsthumsgrenzen der Schimmelpilze unter den obwaltenden Umständen im allgemeinen und nicht vergleichend diejenigen für die einzelnen Stadien festzustellen. Da die Spore die wesentlich resistentere Form ist, so kam sie, wie bereits erwähnt, zur Verwendung, und es verstehen sich daher in sämmtlichen Tabellen die Resultate lediglich fuir Sporenimpfung.

Nach den Erfahrungen an Mucor, Aspergillus und Botrytis zeigte sich Penicillinm aussergewöhnlich resistent gegen den Einfluss von Metallgiften, insonderheit des Kupfervitriols ${ }^{2}$ ). das sich sonst den Pflanzen gegenüber als ein starkes Gift erweist ${ }^{3}$ ). Da sich in Folge

1) Flïgge, Yilirurgrganism+n, JI. Aufl., Md. J. 1. t.1.

2! I. of? , fiftwirkungen, 1). 36.

3) Iagti, Uligulyuan. Erscheinungen is lebenden Zellen, 1 s:t:3. 
dessen die Tersuche mit diesem Pilze sehr viel weiter ansdehnen liessen und im Sinne rler Albeit erfolgreicher gestalteten, so werde ich bis auf einige nothwendige Andentungen ïber dicse Ertolge mit Penicillium die gesammten Resultate der übrigen drei Pilze vorweg heloandeln.

Zunächst kam es darauf an, die Wachsthumsgrenzen fuir einen Pilz festzustellen, welcher an das betreffende Gift in keiner Weise gewöhnt war; dementsprechend wurden also zuerst Sporen von giftfreien Reinkulturen zur Impfung verwendet.

Bei meinen diesbezïglichen Versuchen, die sich zunächst nur auf Salze der drei Metalle: Kupfer, Zink und Nickel, erstreckten, stellte sich mun als geneinsam für sämmtliche vier Schimmelpilze - also mit Einschluss des I'micillimm - nur die u. a. durch rie Arbeit von Richal'is ${ }^{1}$ ) bekannte 'Thatsache heraus, dass kleme Mengen jener Metallgifte ein Wachsthumsvermehrung veranlassten, eine geringe Zumahme derselben aber schon hemmend wirkte. Denn ein nur mässiges Uebensteigen der Concentration, welche den Beschlemnigungsreiz ausubte, liess ball - wenn auch nicht bei l'enicillimm, der sich, wie gosagt, als sehr resistent erwies, so doch bei den anderen durch die Zeitunterschiesle eine dentliche Entwickelungshemnung, und eine nur geringe weitere Erlöhung des

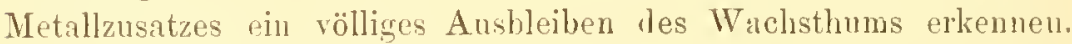

Die folgente Tabelle. welche einen Auszug aus den im Anling gegebenen ausfülrliclien T'abellen der Tab. I rlarstellt, giebt zum leichteren Vergleicl der Resistenz dieser drei Schimmelpilze die Grenzwerthe der Concentrationen für die Möglichkeit rler Fintwickelung und Fructification.

\begin{tabular}{|c|c|c|c|c|c|c|}
\hline \multirow[b]{2}{*}{$\begin{array}{l}1 \text { tiramm- } \\
\text { molekiil } \\
\text { s'elüst }\end{array}$} & \multirow{2}{*}{\multicolumn{2}{|c|}{$\begin{array}{l}\text { Mucor mucedo } \\
\text { Ent- } \\
\text { wickeluug } \\
\text { Fication }\end{array}$}} & \multicolumn{2}{|c|}{ Aspergillus niger } & \multicolumn{2}{|c|}{ Botrytis cinerea } \\
\hline & & & $\begin{array}{l}\text { Ent- } \\
\text { w irkelung }\end{array}$ & $\begin{array}{l}\text { Fructi- } \\
\text { fication }\end{array}$ & $\begin{array}{l}\text { Eut- } \\
\text { wickelung }\end{array}$ & $\begin{array}{l}\text { Frueti- } \\
\text { fications }\end{array}$ \\
\hline ' & in 20001 & in 20001101 & i]) 21$)(1011$ & i1) $2(x)+1$ & in 20401 & in $\underline{y}(1)(x)$ I \\
\hline 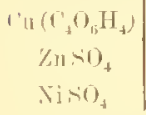 & 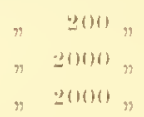 & 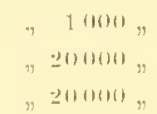 & 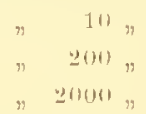 & $\begin{array}{c}n \quad 10 " 1 \\
" \quad 200, " \\
n \quad 20001, n\end{array}$ & $\begin{array}{l}111 \% \\
3011 n \\
21)(111 \%\end{array}$ & 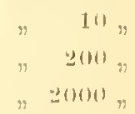 \\
\hline
\end{tabular}

Abgeselzen von der relativ geriugen Resistenz des Mucor im allgemeinen, die bei einer mäheren Betrachtung der eingehenderen

1) Kichards, Jahrl. f. wist. Butan., Bel. XXT, 18s7: "Ueber dip Becinflusung durch vinem. lieize:" 
Tabellen durch die Zeitunterschiede - da die retardirende Nebenwirkung des osmotischen Druckes bei solchen Verdünumuen belanglos ist - noch deutlicher erkennbar wird, kennzeichnet sich dieselhe den andern beiden Pilzen gegenïber ganz erheblich in dem Unterschiede der Concentrationsgrenzen für die Fructification. Nach den Resultaten der eingehenderen Tabellen der Tab. I komnte die Keimung der Sporeı der drei Pilze sowie ibre Entwickelung zu einer Decke beziehungsweise einer Insel - abgesehen von dem Verhalten des Aspergitlus gegenüber dem Zinksulfat - bei einer Concentration von 20000 Litern in allgemeinen als normal bezeichnet werden; die Zeiträume hingegen, welche bis zur Fructification gebraucht wmden. lassen schon bei dieser schwachen Concentration auf einen hemunenden Einfluss der Metallgitte fiir den Organismus der Pilze schliessen. Es schien in dieser Concentration der Uebergang von einer vortheilhaften zu einer uachtheiligen Beeinflussung durch chemische Agentien zu liegen. Denu schou die nächste Erhölıung derselben um das Zelınfache liess ibre ausgesprochen hemmende Wirkung erkemnen, welche bei dem empfindlichsten der drei Pilze, dem Muror, schon ein völliges Ausl)eiben cler Fructification zur Folge liatte. Eine weitere Verdoppelung des Metallsalzgehaltes. also eine Concentration von 1000 Litern. machte dann schon jerle Entwickelung auf diesen Giftmerien wenigstens für J/ucor - unmöglich, wähırend diese Grenze für die beiden andereı etwas höher" lag.

Ausser für Mucor fiel diese entwickelungshemmende Concentrationsgrenze mit der letalen nicht zusammen. da diese Sporen nach wochenlanger Incubation in dem Giftmedium dennoch bei vorsichtiger Uebertragung in giftfreje Nährlïsung mit wenigen dusnahmen die erhaltene Entwickelungsfähigkeit zeigten.

Es erübrigt nun noch, beror ich zur Betrachtung der Versuche mit dem weinsauren Kupferoxydnatrinm iibergehe. auf die auffullend grössere Resistenz des Aspergillus nige gegeniiber dem Zinksulfate hinzuweisen, eine Beobachtuns, iber welche bereits Raulin') einige Angaben macht.

Eine Concentration von 2000 Litern, welche bei Botrytix selion eine zeitlich deutliche Hemmung in allen drei Phasen, hei M/nor aber bereits das gänzliche Ausbleiben der' Fructification verursacht, schien bei lspergillus wiger ein absolut normales, hinsichtlich ther

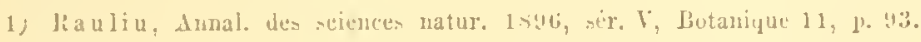


Hyphenstärke fast gïnstiges Wachsthum zu bewirken. Anch bei der zehnfach stärkeren Concentration ist der analoge Unterschied dem fiotrytis gegenüber noch rentlich erkennbar.

Anschliessend an die immerhin geringe Resistenz dieser drei Schimmelpilze gegeniiher der Einwirkung dieser drei Metallsalze babe ich entsprechende Versuche mit einer solchen Verbindung gemacht, in welcher dis Kujfer nicht als solches allein, sondern als Complex auftritt; und zwar eignete sich dazu besonders das weinsaure Kupferoxydnatrium. Die Lösungen wurden auf die Weise hergestellt, dass analog dem angegebenen Verfahren die entsprechende Menge des in Wasser wenig löslichen weinsauren Kupferoxydes mnter Zusatz von Natronlauge gelöst, und nach der Vereinigung mit der Nährlösung die Gesammtmenge mittelst Weinsäure schwach angesänert wurde.

Interessant war nun die Beobachtung, welche in der Arbeit von Paul \& Krönig ${ }^{2}$ ) eingehende Berücksichtigung findet, dass auch gegenüber allen drei Schimmelnilzen — wie das anch relativ bei Penicillimm glamcum hervortritt und dort eingehender erwähnt werden wird - die entwickelungshemmende bezw. törltliche Giftwirkung des Kupfermetalles, dessen Wirkung besonders einigen höheren Ptlanzen gegenitber bekaunt ist"), in dieser Complexverbindung ganz bedeutend vermindert wird.

Fiur Mucor lag die Grenzconcentration hinsichtlich des Kupfergehaltes um das Finffache höher als beim $\mathrm{CuSO}$. Lwpergillus und Botrytis, deren Entwickelung auf einer Kupfersulfatlösung bei etwa 1000 Litern ihre Grenze erreicht hatte, zeigten für die Complexverbindung noch bei 10 Litern ein als absolut normal zu bezeichnendes Wachsthum, welches erst bei 5 Litern gänzlich ausblieb.

Allerdings zeigt sich auch hiel dieselbe Abstufung in de Resistenz dieser drei Pilze; immerhin aber sind die Concentrationsgrenzen fü die Entwickelung und das Wachsthum, also diejenigen Concentrationen, welche das Wachsthum verhindern, doch ganz erheblich hinaufgeriickt.

Nebenbei sei hier bemerkt, dass bei diesen letaten Versuchen mit L preryithrs die Beobachtung von Wehmer ${ }^{3}$ ) ïber die Bildung

1) l'aul \&rönig, l.c.

2) Tach Nägeli, Oligulynam. Ersheinumgen in lebend. Zellen, 1s93, tödtetis noch rin Theil kupter un Lum Millimen Thoile Wasiors cineu cinzeluen Faden von Spirogyra.

3) Welmer, Butan. Ztg. 1s91, T. 233. 
vom Oxalsäure als Stoffwechselproduct dieses Pilzes in der Abscheidung gut ausgebildeter rhombischer, blaner Krystallnadeln von unlöslichem Kupferoxalat ilıre Bestätigung fand.

Nach der Feststellnng dieser Wachsthumsgrenzen fiir die Pilzsporen giftreier Kulturen musste sich an das Ergebniss die schon erwähnte Frage anschliessen, auf welche ich bei Gelegenheit der Versuche mit Penicillium näher eingehen werde, nämlich: ob diese somit dargethane, relatir geringe Resistenz sich durch allmähliche Gewöhnung an das Gift. also durch Accommodation, vergrössern lässt.

Nach Erfahrungen an Penicillium glancum, wo die Wirkung der Accomodation in hohem Maasse bemerkbar wurde, war, wenn auch nicht in demselben Grade, eine Stärkung der Resistenz auch bei diesen andern drei Pilzen allerdings zu erwarten. In der That aber war - wie bei gewöhnlichen Sporen von Penicillium schliesslich im Laufe einer sehr langen Incubationszeit von 4 Monaten ${ }^{1}$ ) eine Accommodation des Indiridunms selbst bemerkbar wurde bei jenen eiumal die Wirkung dieses Vorganges nicht festzustellen; zum anderu ergaben aber meine Versuche trotz mehrfacher Umimpfungen auf demselben Giftmedium so geringe Unterschiede in den Grenzwerthen für die Entwickelung und die Fructification, dass es mir uunöthig erscheint, die näheren Daten inzugeben, sofern sie überhaupt darauf Anspruch machen kömmen, als ansschliessliche Resultate einer Accommodationswirkung zu gelten. Ich glaube mich anf die Mittheilung meiner dabei gewonnenen Vermuthung beschräuken zn kömen, dass auch, wie anzunehmen ist, die Möglichkeit einer Anpassung und damit einer Steigerung der Resistenz für diese drei Schimmelpilze vorzuliegen scheint, dass es aber kaum gelingen wird, die oben gefundenen Maximalwerthe für die Wachsthumsgreuzen um das zehnfache zu erhöben.

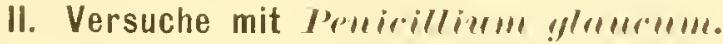

Viel resistenter als die drei vorhergehenden Schimmelpilze hat sich nun Penicillium erwiesen. Und zwar scheint gerade die Art Penicillium ..glnucum" diese Eigenschaft so grosser Resistenz gegen Detallgifte, insonderheit gegen Kupfersalze, zu besitzen. Allerdings habe ich Impfungen mit andern Arten dieser Gattung niclıt angestellt;

1) Vergl. 1. 17 und die Tabellen der Tab. I. 
ans dem Unstande aber, dass die spontane Infection mittellochnud hochconcentrirter Kupfersulfat-Nährlisungen, welche ich offen an verschiedenen, geeigneten Orten - sich selbst iiberlassen lange Zeit aufgestellt hatte, stets nur die Fntwickelung eines Penicillinum erkennen liess, welcher mit dem Penicillinm glancum identisch zu seil schien, - aus diesen immer sich wiederholenden Tumstande glaube ich schliessen zu dürfen, dass andere Arten dieser Gattung nicht diese Widerstandsfälnigkeit oder wenigstens nicht das Anpassungsvermögen in so hohem Maasse besitzen, welches schliesslich diese Art doch befähigte, auf so hochconcentrirten Lösmgen del Metallgifte zu gedeihen.

Wemn ich num wiederum vorerst im Hinblick anf die Wachsthunsgrenzen eines Pilzes von giftfreier Kultur die Resultate sümmtliclıel' chiesbezuglicher Tabellen der Tab. I kurz zusammenfasse, so muss man binsichtlich der hemmenden Wirkung der Salze auf die Entwickelmug dieses Pilzes die in folgender Tabelle angegebene Reihenfolge aufstellen, in welcher die Zahlen diejenigen Concentrationen angeben, welche als Gronzen noch die Entwickelıng und Fructification des Pilzes zuliessen.

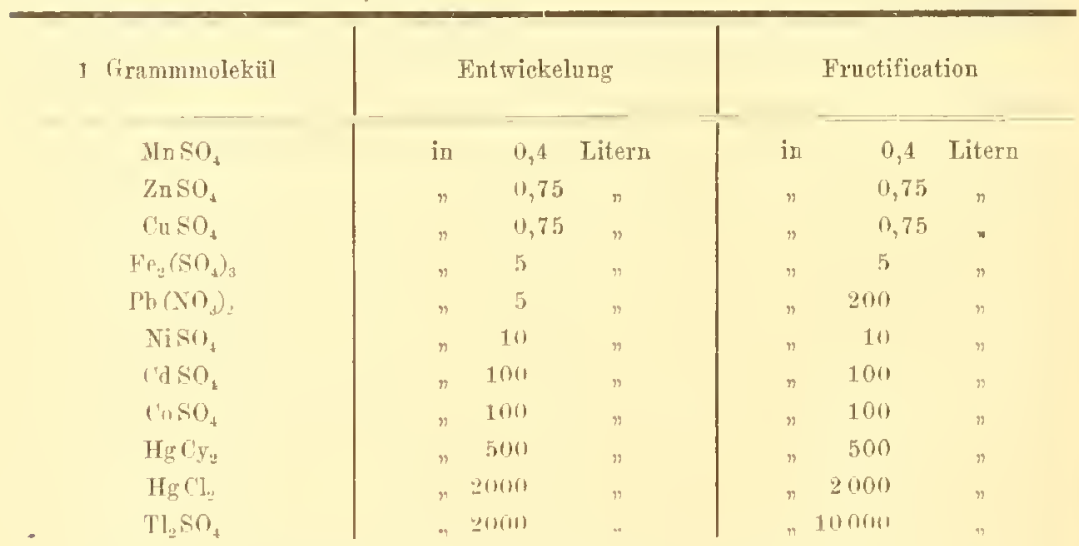

Diese Anordnung der Salze - deren Anzahl ich für die Versuche mit Penicitlinu, wie vorluer erwälnt, noch um acht weitere vermelurt babe - mach ihrer entwickelungsluemmenden Wirkung silt, whl bemerkt, fïr die Sporen eines Pilzes von giftfreier Kultur, und zwar stimmt dieselbe in wesentlichen mit der von Clark ${ }^{1}$ ) angegebenen, wenn anch nicht bezüglich der Höhe der Concen- 
trationen, so doch des Grades der charakteristischen Giftwirkung der Metalle ïberein.

Wenden wir um in Anschluss an diese Anordnung der Salze unsere Betrachtung den eingrehenderen Tabellen der Tab. I zu, so erscheint:

das Mangausulfat ( $\mathrm{MnSO}_{t}$ ) dem Wachsthum des Penicillium glancum gegenüber in seinen Charakter als Gift in engeren Sinne völlig wirlungslos. Bis zu der Concentration ron 5 Litern war das Wachsthum als absolut normal zu bezeichnen; von der Concentration ron 2 Litern an wal allerdings die Zeit bis zu einer makroskopisch deutlich sichtbaren Keimung eine etwas lïngere, während mit Ausuahme der gesättigten Lösung rou 0,t Literı die Dauer bis zur Fructification constant blieb. Die Pilzlecken selbst waren, nachdem das Auskeimen cinmal begonnen hatte. in kurzer Zeit kräftig und liessen keinerlei benaclıtheiligende Einwirkungen durch das Salz als Gift erkennen.

Dass der Pilz in seiner Entwickelungsperiode bei sol hohen Concentrationen und besonders bei der höchsten. der gesättigten Lösung, eine so gewaltige, zeitliche Hemmung erfälırt, kamn -.. wiewohl auch bei diesem in engeren sime ungiftigen Salze eine grewisse 'Zeit zur Anpassung an dies aussergewöhnliche Medium nothwendig sein wird - immerhin woll der giftigen Wirkung des Metallsalzes allein nicht zugeschrieben werden. Vielmehr darf man nicht vergessen, den mit jeder Concentrationserhöhung steigenden osmotischen Druck in Erwägung zu ziehen, welchen die Pilzsporen zu überwinden gezmnngen waren. und der selbst ebenfalls eine gewisse Anpassungszeit erfordert.

Hinsichtlich dieses Momentes ist zu beacliten, dass beispielsweise der osmotische Druck einer gesättigten Mangansulfatlösung mindestens, also ohne Berücksichtigung der durch molekulare Dissociation bedingten, nicht unerheblicheı Druckerhölıug, demjenigen eines Rohrzuckerlösung von $80-90 "$ ". d. l. etwa 62 Atn. (= 15 " $\mathrm{KNO}_{3}$ - Lösung) entspricht.

Dem Ziuksulfat (ZnSOH $\mathrm{SO}_{4}$ ) kommt erfahrungsgemäss eine sehr starke lesinticireude Wirkung zu; um so mebr muss man über die Concentrationen erstaunt sein, auf welcher Penicillium ylancum! sich zu entwickeln noch im Stande war. Bei der schwachen Lrisung ron 2000 Litern liess sich die bertits erwähnte Begiinstigung des Wachsthums durch chemischen Reiz in einer starken Hyphenentwickelung deutlich erkennen; bei der zehnfach stärkeren Concen- 
tration machte sich, wem auch noch in geringem Grade, eine entwickelungshemmende Finwirkung sowohl in der Zeitdauer als in einer weniger normalen Art und Stärke des Wachsthums bemerkbar. Bei einer weiteren Erhïhung der Concentration blieb dann bis zu einer solchen von 2 Litern die Zeit bis zur Keimung zwar verläugert, aber constant, wïhrend die Weiterentwickelung zu einer festen, zusammenhängenden Decke, sowie besonders die Fructificationsperiode zeitlich eine bedentende, progressive Verzögerung erfuhr, welche iu den noch höheren Concentrationen, zumal in Folge der Mitwirkung der osmotischen Drucksteigerung, sich noch ganz gewaltig vergrösserte. Immerhin war das Wachsthom des Pilzes auf diesem Giftmedium dennoch bis zur höchsten Concentration möglich.

In Berücksichtigung jener Thatsache nun, dass hier die Sporen des Pilzes z. Th. nicht sofort, sondern erst nach 4 Wochen, bezw. yonaten anskeimten, sich dann aber bis zur Fructification entwickelten, kann man ohne weiterès die Annahme nicht zuriickdrängen. dass, solange das änssere Medium nicht sofort abtödtend in den Organismus eingreift, vor dem Auskeimen eine allmähliche Anpassung der Spore an dasselbe stattfindet. Denu wäre dieses nicht der Fall. wäre nicht eine gewisse, mit jeder Erhöhung des Giftgehaltes waclısende Zeitdaner zu solcher Adaptation erforderlich, und würde diese Zeit hier nicht zur Erlangung dieses Zieles nothwendiger Weise verbrancht, so wäre wohl der Grund dafür nicht einzusehen, dass jene Sporen nicht - wenn überhanpt einmal solort zur Auskeimung gelangten, sondern vielmehr erst nach einer so anssergewöhnlich langen Incubationszeit, welche laum allein in der Ueberwindung des hohen osmotischen Druckes ihre Erklärung finden kam. Nach den in dieser Hinsicht gemachten Erfahrungen luben ja auch Lösungen indifferenter Stoffe, wenn anch zeithich nicht in demselben Maasse, einen gleichen Effect. Es liegt somit also hier ene Accommodation des Individumms selbst und zwar an das Gift vor, eine Fähigkeit. welche gerade dem Penicillium glaxcm den andern Schimmelpilzen gegenüber in hohem Maasse eigen zn sein scheint und ihm auf solchen Giftmedien, wo jene ohne getöltet zu sein - versagten, noch eine Weiterentwickelung ermöglicht.

Diese Beobachıtung zieht sich durch sämmtliche Versuche, welche mit Sporen einer giftfreien Kultur auch bezïglich der anderu Metallgifte, vor allem mit dem Kupfersulfat, angestellt wurlen. 
Für die Kulturen anf der Zinksulfatlösung war die intensiy gelbe Färbung der unteren Seite der Hyphendecke clarakteristisch, wïhrend die Conidien und auch die Sporen schneeweiss blieben.

Wie schon eingangs erwihnt, kounte 'Trabut ${ }^{1}$ ) noch anf einer $9^{n}$ " Kupfervitriol ( $\mathrm{CuSO}_{4}$ ) enthaltenden Nühılösung eine Entwickelung und Fructification von Penicillium yluuen beobachten, eine Concentration, welche auch $\mathrm{Clark}^{2}$ ) als Wachsthunsgrenze angiebt. In meinen Versuchen, die allerdings unter anderen Ennährungsbedingungen stattfanden, wurden diese Grenzen ganz erheblich übertrofien. Es vergrösserten sich allerdings. analog dem Terhalten des Pilzes gegen das Zinksulfat, wie ans der Tabelle ersichtlich ist, die Zeiträune bis zum Erscheinen einer makroskopisch wahrnehmbaren Keimung, einer Decke und der Fructification besonders in den hohen Concentrationen ganz bedentend. und machte sich auch hier der entwickelungshemmende Einfluss des Kupfersalzes. der durch Aupassmug ïberwunden werden musste, sowohl dadurch als auch an der schwachen Hyphenentwickelung und den theilweisen Auftreten krauser, welliger Decken statl' bemerkbar. Immerhin aber erreichte der Pilz anch hier, selhst auf einer gesättigten Lösung, wenn auch erst nach 5 Monaten, die Reifeperiode, und zwar traten auf den hohen Concentrationen die Sporentrïger wieder in der gewöhnlichen weissgranen Färbung auf', während dieselbe besonders bei sehr verdinnten Lösungen dieses Salzes eine schwach riothliche war.

Analog den Tersuchen mit den vorher behaudelten Pilzen habe ich auch mit liesem solche bezuighich seines Vorhaltens gegenüber dem Kupter in der complexen Verbindung des weinsaureu Kupferoxyduatriums $\left(\mathrm{Na}_{2} \mathrm{Cu}_{4} \mathrm{C}_{4} \mathrm{O}_{2} \cdot \mathrm{H}\right)$ angestellt und zwar mit dem gleichen Erfolge. Entsprechend der grossen Resistenz dieses Pilzes gegen das Kupfer erfahren hier bei diesem Doppelsalz die Zeitrïume der einzelnen Phasen ganz erhebliche Verkürzungen, besunders in den höchsten Concentrationen, wo ohnedies noch die gewaltige osmotische Druckerhöhnng als besonder's ungünstiges Moment zn berücksichtigen ist. Eine höhere Grenzconcentration als diejenige von 1 Liter war wegen der dann stattfindenden Abscheidum ven Kupferoxydul nicht erreichbar. Gegenüber diesen Resultaten geht die Resistenz des I'cricillizm

1) 1. $\mathrm{c}$,

2) 1,14 
glancum gegen den entwickelungshemmenden Einfluss der andern noch zu behandelnden Metallsalze, welche allerdings ebenso wie die rorhergehenden in sebr geringen Mengen einen das Wachsthum legiinstigenden Reiz ausiibten, ganz erheblich zurück.

Das schwefelsaure Eisenoxyd $\left(\mathrm{Fe}_{2}\left(\mathrm{SO}_{4}\right)_{3}\right)$ verhinderte bei einer Concentration von 4 Litern bereits jegliche Entwickelung des Pilzes auch nach wochenlanger Incubation der Sporen; nur bei einer Lösung von 5 Litern war dieselbe noch möglich, doch zeigte sich hier wie schou bei einer solchen von 10 Litem der wachstlumswidrige Einfluss des Salzes in der sehr schwachen und anomalen Weiterentwickelung der Hyphen ausserordentlich deutlich.

Aelnlich waren die Erfolge mit dem salpetersauren Blei $\left(\mathrm{Pb}\left(\mathrm{NO}_{3}\right)_{2}\right)$, wo das Auskeimen der Sporeu zwar noch bei einer Concentration von 20 bis zn 5 Litern anfwärts - allerdings erst nach - - 3 Wochen - möglich war, und eine Weiterentwickelung zu kleinen kugeligen, submers wachsenden Hyphengebilden deutlich sichtbar wurde; eine Decke aber und die Sporenbildnng kam nur noch bei einer Terdïnnung von 200 Litern zu Stande.

Die Entwickelung des Pilzes auf einer Nickelsulfatlösung $\left(\mathrm{NiSO}_{4}\right)$ glich in allgemeinen bis zn einer Concentration von 20 Literu derjenigen auf dem Kunpersulfat; bei den stärkeren Concentrationen jedoch zeigte das Metallsalz sehr bald, wie aus der Tabelle ersichtlich ist, seinen für das Wachsthum des Pilzes nachtheiligeren Charakter. Allerdings war noch bei einer Concentration ron 10 Literu eine Entwickelung bis zur Reife möglich, doch war dieselhe eine ebenso langsame wie kümmerliche; den Eintuss einer Concentration von 5 Litern waren die Pilzsporen, ohne getödtet zu werden, dennoch durch Anpassung an das Gift nicht mehr im stande, zu iiberwinden.

Relativ noch weniger resistent erwies sich der Pilz gegenüber dên schwefelsanren Salzen des Cadmium und Cobalt (CdSO, und $\left.\mathrm{CoSO}_{4}\right)^{1}$ ); und zwar kann ich wegen der Analogie der Resultate meine Wahrnehmungen für beide Salze dahin zusammenfassen, dass die Entwickelung des Pilzes, besonders im ersten Stadium, bei einer Concentration von 200 Litern im allgemeinen noch eine relativ

1) Nach sia usuru (Recherch. chimiq. 1sil, p. 20s) und Boussingaut (Agronom. etc. 1868 , Bi. IV), p. 300) ist (o für die Pflanzen anch in grosser Meuge sehr untergeorduet giltig. 
gute zu nelmen war. Bei einer Concentration von 100 Litern wuchsen allerdings sowohl die Zeiträume, die zur Anpassung an das Gift gebraucht wurden, als auch die Mangellaftigkeit der Hyphenbildung sclıon ganz gewaltig; und bereits mit einer Lösung ron 50 Litern - also $0,65^{\circ} \%$ des krystallisirten Salzes - war die Grenzconcentration, welche also jede Entwickelung auf diesem Medium verhinderte, erreicht.

Wie zu erwarten war, konnte die Widerstandstahigkeit des Pilzes gegen die Wirkung der beiden als höchst giftig bekannten Qnecksilbersalze, des Cyanides und des Chlorides ( $\mathrm{HgCy}_{3}$ und $\mathrm{Hg} \mathrm{Cl}_{2}$ ), hohe Grenzen nicht erreichen. Allerdings war die entwickelungshemmende Wirkung der Cyanverbindung der des Chlorides gegenüber eine gemilderte. Denn während eine Sublimatlösung vou 1000 Litern jede Entwickelung auch nach langer Incubation verhinderte ${ }^{1}$ ), setzte das (yanid dem Vachsthum des Pilzes elst bei einer Concentration von 200 Litern die Grenze, ein Wirkungsunterschied, der wohl in dem rerschiedenen Grate der nolekularen Dissociation, auf deren vermuthlichen Einfluss ich uoch später zuriickkomme, seine Erklärung findet.

Die relativ geringste Resistenz zeigte der Pilz gegenüber dem 'Thalliumsulfat ( $\mathrm{Tl}$. SO $\mathrm{SO}_{1}$ ), dessen tödtender Wirkung für Algen auch von Loew ${ }^{2}$ ) gedacht wird. Während anf einer Concentration ron 2000 Litern zwar noch eine Entwickelung bis zn schmalen Inselstreifen, die aber die Reifepreriode nicht erreichen komnten, möglich war, wurde eine solche auf einer Lösung von 1000 Literı durch den Einfluss des Giftes auch nach wochenlanger Incubation völlig verlindert.

Bei allen diesen Angaben über die Grenze des Wachstlıms unter dem Einfluss der verschiedenen Salze wïre es nicht zutreffend, die jeweils in Frage kommenden Grenzconcentrationen auch zugleich als letale, d. I. diejenigen zu bezeichnen, welche ein Absterben der Sporen bewirken, ein Fall, welchen anch Nägeli ${ }^{3}$ ) hinsichtlich der Bakterien für Carbol- und Salicylsäure bei der Gührthätigkeit feststellte. Vieluehr hat sich. wie bei den vorhergehenden nit wenigen Ausualimen, so anch bei Penicitlium ylancum - mit Ausschluss der Versuche mit Sublimat, das sehr bald die

1) Luen, Giftwirkment, 4. 35 16. 53.

2) Loew, Giftwirkungen, y. 3i.

3) Nägeli, Die niederen Pilze, $1 \times 77$, p. 27, 2us u. s. w. 
Sporen tödtete, - durch entsprechendes vorsiclitiges Ueberimpfen auf giftfreie Nährlösung die im Falle einer Niclıtentwickelung anf der Giftlösung dennoch erhaltene Keinfähigkeit der Sporen fast überall nachweisen lassen. Es lag somit also im allgemeinen bei deu gefundenen Concentrationsgrenzen für das Wachsthum der Pilze zunächst nur eine entwickelungshemmende Wirkung der Gifte vor. Ob diese in entsprechender Concentration bezw. nach entsprechender Einwirkungsdaner schliesslich, wie allerdings anzunchmen wäre, in eine tödtende übergeht, und wie hoch diese Concentrationsgrenzen liegen, diese Frage genauer zu unterstchen, lag ausserhalb des Rabmens meiner Arbeit.

Ich möchte nur noch beifügen, dass gegenüber der resistenten Dauerform, der Spore, iu einigen Parallelkulturen, welche ich zu diesen Zwecke mit den Hyphen von Penicillinm ylunum in analoger Weise auf Kuptersulfatlösungen anstellte, diese letzteren sich als ungleich empfindlicher erwiesen ${ }^{1}$ ).

Im Rückblick auf diese gesammten Erfolge mit Penicillinm ylun muss man zusammenfassend zu dem Urtheil gelangen, dass dieser Schimmelpilz sich zwar gegenüber dem Thalliumsulfat und den beiden Quecksilliersalzen wach den gemachten Erfahrungen im Terlältniss zu anderen pflanzlicheu Organismen bezïglich seiner Resistenz uicht erheblich auszeichnet, wohl aber den übrigen Metallgiften gegenüher. Insonderheit ist die ganz aussergewöhnliche Widerstandsfähigkeit gegen das Zink- und das Kupfersulfat, auf deren gesättigten Lösungen die Sporen sogar im Stande waren, sich zu entwickeln, auffallend.

Unschwer knïpft sich daran - besonders in Anlehnung an die Versuche mit den beiden Quecksilber- und Kupfersalzen die Frage nach der Ursache dieser Verschiedenheit der- Wirkung der Salze bei gleichem Metallgehalt auf das Leben des pflanzlichen Organismus. Bei der Beantwortumg dieser Frage kam man, gestiitzt auf die vorliegenden Arbeiten von Clark, Stevens und Paul \& Krönig *) wohl geneigt sein, auch für meine Resultate die Erfalarungen ïber die elektrolytische Dissociation der Moleküle und ilıre physiologische Bedeutung erlilïrend heranzuziehen.

Wie bekannt, erleiden die Mfetallsalze besonders in wässeriger Lösung eine theilweise Spaltung ihrer Moleküle, d. h. elektrolytische

1) Vergl. p. 9.

$=1$. 
Dissociation; und zwar steigt diese mit der Zmahme der Verdiinnung, sodass in unendlicher Verdiinumg völlige Dissociation herrscht. In Folge dieses chemisch-physikalischen Vorganges wird die physiologische Wirkung eines solchen Metallsalzes in wässeriger Lösung nicht eine einlıeitliche sein; vielmeh" wird sie neben der der geschlussenen noch ron derjenigen der dissociirten Molekiile. also der Ione - des Metall- und des Säure- Lon - und zwar je nach dem Grade der Dissociation von der Anzahl dieser activen Ione abhängig sein.

Mit Ausschluss des Bleisalzes, der Quecksilber- und des weinsauren Kupfersalzes habe ich nu die schwefelsauren Verbindungen der Metalle in die Versuche lineingezogen. Da stets molekulare Lösungen zur Verwendung kamen, so ist das Anion in den entsprechenden Parallelversuchen qualitativ stets ras gleiche.

Das Mangansulfat erschien aber, wie ja auch ron den Sulfaten Aler Alkaligruppe bekannt ist, für die Entwickelung des L'enicillium den andern Metallsalzen gegenuber als Gift nahezu wirkungslos. Demnach musste, da die TVirknng des Säureions sich qualitativ deckte, bezüglich der andern Salze entweder dem Metall-Ion oder aber dem nicht dissociirten Theile der Sulfate in seiner specifischen Eigenschaft als Gift jeweils der alleinige, oder schliesslich dem activen Metall-Ion eine betheiligte Wirkung zugeschriebon worden.

Ist nun in der That die physiologische Giftwirkung eines Metallsalzes von derjenigen des Metall-Ion und damit von der Dissociation abhängig, so erklärt sich daraus auch unschwer die grössere entwickelungshemmende Eigenschaft des Kupfersulfates gegeniilser der weinsauren Complexverbindung: wie aucl des Quecksilberchlorides gegenïber dem Cyanid. Bei dem ersteren stehen sich Kupfer- und Kupfer-Natrinm-Ion bei gleichem Kupfergehalt, hei den andern beiden -- in Folge grösserer Dissociation des Chlorides - gleichartige active Ionen bei ungleicher Anzahl gegenüber,

Nachdem so durch die Versuche mit den Sporen eines nicht an die betreffenden Gifte gewöhnten Pilzes die Wachsthumsurenzen festgelegt waren, konnte der Frage der Accommodation, zu deren eingehenderen Behandlung sich im Gegensatze zu den drei ursten Schimmelpilzen Penicillinu glanemm in Fulge seiner grossen Widerstandsfäligkeit ganz besonders eignetc, uäher getreten werden. 


\section{Ist Penicilliume ylerur/!"! anpassungsfähig? Welches sind die Wirkungen der Accommodation?}

Die Accommodation lebender Organismen an gewisse äussere Bedingungen und Verluältnisse, welche łem Bedürfniss ihrer Natur im allgemeinen nicht entsprechen, ja oft sogar zuwiderlutuen, bezüglich der Temperatur, des Lichtes, der Nahrung oder der Anwesenheit solcher Stoffe, welche man wegen ihrer dem Leben und der Entwickelung entgegenwirkenden Eigenschaften als "Gifte" bezeichnet, ist eine bekannte Erscheinung. Allmïhliche Gewöhnnng an solche anomalen Umstände und Stoffe mit stufenweiser Steigerung bewirken erfahrungsgemïss nach und nach oft einen solchen Zustand und Grad des Angepasstseins in den Lehensfmctionen des betreftenden Organismus, dass eine plötzliche Aufluebung bezw. Entfernung dieser in Grmudr zwar anomaten Verhältnisse dennoch die Weiterentwickelmg desselben nicht nur nicht beginstigen. sondem oftmals - wenigstens eine Zeit lang - uachtheilig beeinflussen kann.

Treftende Beispiele lierfür bieten unter anderen die sog. Arsenikesser, Morphinisten, Cocänisten ${ }^{1}$ ); denn während unter anderem schon 0,1 g arseniger Säure genügt, einen Menschen unter normalen Bedingungen zu tödten, kann bei allmählicher Gewöhnung die vierfache Dosis ohne Schaden ertragen werden ${ }^{2}$ ), eine plötzliche Entziehung aber wird, wie bekamt, zumeist eine wenigstens eine Zeit lang andauernde Benachtheiligung des betreflenden Individuums zur Folge haben.

Beim Studinm der Entwickelungsgeschichte der organischen Welt kommt man iuberall anf dieses wichtige Moment der Anpassung zuriick, indem sie für die Wandlung ganzer Arten bedeutungsvoll geworden ist.

Dahingehende Versuche sind sowohl im Thier-wie im Pflanzenreiche in mannigfacher und zahllreicher Weise angestellt worden. Aus diesem letzteren Gebiete möchte ich unter anderen der Versuche gedenken, welche in diesem simne mit niederen Pilzen und Bakterien von Eréra ${ }^{3}$ ), Kossiakoff ${ }^{1}$ ), Trambusti $)$,

1) Loew, riftwirkungen.

2) ebeuda, 1. 20 .

3) Eréra, Reforat i. d. Botan. Zeitung No. XT (Juni 1s!y!), 1. I fo?.

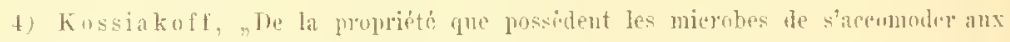
milienx antiseptiques". Imal. 1. l'instit. Pastenr, $1^{n}$ amm. Outubre $18 x \%$.

5) Trambisti, "ontributio sperimentale alle legge dell adattamento dei nicroarganisui sni mezzi untisettizi“. Lo Sperimentale XIVI, 1892. 
Galeotti ${ }^{1}$ ) und Dieudonné $\left.{ }^{2}\right)$ und zwar sämmtlich mit dem gleichen Erfolge der Erhöhung der Resistenz durch Accommodation gemacht worden sind.

In wie geringem Maasse democl diese Wirkung bei den vorerwihnten drei Schimmelpilzen trotz einer allmählichen, in stufenweiser Generationsfolge vorgenommenen Gewöhnung sich äusserte, wurde oben ${ }^{3}$ ) bereits gesagt. Nach den Erfahrungen über die resistente Entrickelungsfähigkeit eines Penicillum glumeum auf einzelnen Metallgiftlösungen und das damit zusammenhängende, bereits grosse directe Anpassungsvermögen der Sporen einer giftfreien Kultur war aber bei einer Gewöhnung mehrere Generationen hindurch ein im Sinne der Arbeit sehr günstiges Resultat zu erwarten. Allerdings kounte die der Resistenz und Entwickelungsfähigkeit gïnstige Wirkung solcher Accommodation nicht für alle Metallgifte lediglich durch eine Erweiterung der Wachsthumsgrenzen, also durch eine Erhöhung der entsprechenden Grenzconcentrationen sich kenntliclı machen, da u. a. bei den Zink- und Kupfersulfat lie höchstmögliche Concentration bereits in den Versuchen mit einem $\mathrm{Pilz}$ von giftfreier Kuntur erreicht worden war. Dennoch aber kounte sie sich in einer wesentlichen Verkiirzung der Zeiträume und einem entsprechend besseren Wachsthnn äussern, wie dies auch in der Tlat der Fall war.

Bei der Ausfïhrung dieser Accommodationsversuche war, um das Optimum der Resistenz und Entwickelungsfähigkeit auf solchen Giften zu erreichen, der gegebene Weg derjenige, die Concentrationen ron Generation zu Generation stufenweise zu erhöhen. Dis geschah so, dass die Sporen eines Pilzes, der auf einer schwachen Metallgiftlösung gewachsen war, jeweils auf eine entsprechend höhere Concentration geimpft und die sporen dieser neuen Kultur wiederum auf die nächst hölıere Concentration übertragen wurden.

Die für die Resultate dieser Versuche aufgestellten Tabellen entsprcchen in der Anlage im wesentlichen denjenigen des ersten Theiles; sie unterscheiden sich uur dadurch, dass einmal die An-

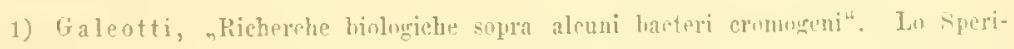
mintale ILVII, $18: 12$.

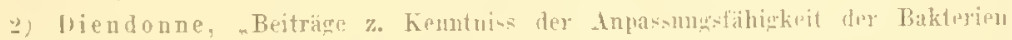

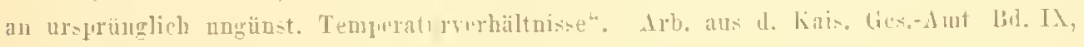
1. Heft, Beriu 1.493.

3) Yurgl. 1. 1:. 
gaben des Procentgchaltes an reincm Metalle und krystallisirtem Salze fortgelassen sind, zum anderen diejenige Columne, welche angiebt, von welcher Kultur dic geimpften Sporen stammen, einige Erweiternngen erfahren hat. Da hier nicht, wie in den dortigen Versuchen, lediglich Sporen von giftfreier Reinkultur zur Verwendung liamen, so findon sich der oben angegebenen Methoule ler Inpfung entsprechend in der fraglichen Verticalreihe eine oder mehrere Zahlen, welche in absteigender Reihenfolge in Litern dio Stärkc der Lösungen angeben, auf denen die früheren Generationen nacheinander in aufsteigender Reihenfolge, also mit steigender Concentration, erwachsen sind.

Analog der Anordnung des vorhergehenden Theiles gehe ich vorweg wiederum eine kurze Tabellc. welche prallel zu jener') die durch Accommodation erzielte Erweiterung der Grenzwerthe für die Möglichleit der Entwickelung und Frnctification des Pilzes und eine damit zusammenhïngende Verschiebung in der Reihenfolge der Metallsalze hinsichtlich des Grades ihres entwickelungshemmenden Charaliters erkennen lässt.

\begin{tabular}{|c|c|c|c|c|c|c|}
\hline 1 Grammmolfkül & \multicolumn{3}{|c|}{ Entwickelung } & \multicolumn{3}{|c|}{ Fructification - } \\
\hline $\mathrm{MnSO}_{4}$ & in & 0,1 & Litern & in & 0,4 & Liter'n \\
\hline $\mathrm{ZnSO}$ & $n$ & 10,75 & $n$ & $"$ & 0,75 & $n$ \\
\hline $\mathrm{CuSO}_{4}$ & $"$ & 11,75 & $"$ & $"$ & 0,75 & $"$ \\
\hline $\mathrm{NiSO}_{4}$ & " & 1 & $"$ & " & 3 & $n$ \\
\hline $\mathrm{Fe}_{2}\left(\mathrm{SO}_{4}\right)_{3}$ & $"$ & 5 & $"$ & $"$ & 5 & $n$ \\
\hline $\mathrm{Cd} \mathrm{SO}_{4}$ & $n$ & 10 & $n$ & $"$ & 50 & $"$ \\
\hline $\mathrm{CoSO}_{4}$ & $"$ & 54 & $n$ & $"$ & 50 & $n$ \\
\hline $\lg \mathrm{Cy}_{2}$ & $"$ & 50 & $n$ & $"$ & 50 & $n$ \\
\hline $\mathrm{Pb}\left(\mathrm{NO}_{3}\right)_{2}$ & & 5 & " & & 200 & $"$ \\
\hline $\mathrm{Tl}_{2} \mathrm{SO}_{4}$ & & 000 & $"$ & $"$ & 1000 & $"$ \\
\hline $\mathrm{HgCl}$ & , & 600 & $"$ & $"$ & 2000 & $"$ \\
\hline
\end{tabular}

Bei den ersten 3 Salzen konnte, wie bereits erwähnt, eino absohut liöhere Wachsthumsgrenze nicht erreicht werden; anders ist es für die folgenden bei einem Vergleich mit jener Tabelle ${ }^{1}$ ). Das Nickelsulfat riickt vor das Eisensalz, wälhrend das Bleinitrat hinter dem zur Accommodation für den Pilz scheinbar geeigneteren Quecksilbercyanid seinen Platz findet; anch das Thalliumsulfat erlaubt im Gegensatze zu dem in der vorigen Tabelle relatir 
weniger giftig erscheinenden Quecksilberchlorid eine bessere Anpassung.

Bei nïherer Betrachtung der eingehenderen Tabellen der Tab. II werden sich mun folgende Resultate elgeben:

Zunächst machte sich bei den Tersuchen mit den ersten 3 Salzen die grosse Accommodationsfähigkeit des Pilzes an das Gift und ihre Wirkung mit Berỉcksichtigung der osmotisclien Verluältnisse demnoch in einer erheblichen Verkiurzung der Zeiträimme fiir alle drei gegebenen Phasen und ein sehr viel kräftigeres Wachsthum der Hyplien deutlicl erkennbar.

Das Mangansulfat (MnSO, liatte sich gemïss der Versuche mit Sporen einer giftfreien Reinkultur für die Entwickelung derselben in seiner Giftwirkung im engeren Simne als völlig unschädlich erwiesen. Dementsprechend konnte eine etwaige Wirkmg der Gewöhnung an diesen der Natur des Pilzes zwar immerhin mehr oder weniger fremden Stotf doch nicht in dem Maasse wie bei den anderen Salzen zum Ausdruck kommen. Allerdings neisen die einschläglichen Tabellen der 'Tab. I und II in den hohen Concentrationen Zeitunterschiede auf, doch sind diese verhältnissmässig so geringe, dass der Grund dafiir zum grössten Theile in der Anpassung an die osmotischen Druckunterschiede gesucht werden muss.

Bei dem Zink- und dem K upfersulfat (ZnSO, und $\mathrm{CuSO}_{4}$ ) macht sich die schnelle Accommodation des Pilzes an den ent. wickelungshemmenden Charakter ler Gifte, der trotz der hohen Wachsthumsgrenzen im ersten Theile der Arbeit imnerhin doch vorliegt, schon erheblich mehr bemerkbar.

Bei den Untersuchungen auf dem Zinksalze unterschielen sich die Sporen eines Pilzes, welcher anf einer Concentration ron 200 Litern gewachsen war. zwar von solchen einer giftfreien Reinkultur; abgesehen ron dem kräftigeren Wachsthum der späteren Decke, in der Entwickelung zeitlich nicht. Die Sporen einer Generation zweiten Grades liessen jedoch rurch die ganz erheblichen Zeitunterschiede - wie aus ler zweiten Horizontalreihe dieser Tabelle hervorgeht - neben der kriftigeren Hyphenentwickelung die Wirkung einer stattgefundenen dupassung an das Gift als solches deutlich erkemen. Gemiiss der Tab. I waren zur Kemung: Deckenbildung und Fructification auf einer Concentration ron 2 Litern jeweils 8. 24 und 35 Tage erforderlich, wiihrend nach der Tabelle der L'ab. II die Sporen eines $(5 * 200)$ accommodirten Pilzes dagegen jeweils nur 2, 3 uul 10 'Tage gebrauchten. 
Allerdings ist bei einer Concentration von 2 Litem der osmotische Dunckmterschied, welchen Sporen einer giftfreien Reinkultur gegeniiber denen eines anf emer Concentration von 5 Litern kultivirten Pilzes bei der Entwickelung zu überwinden haben, ein nicht unerheblicher; inmerhin aber ist die retardirende Wirkung desselben -- besonders mit Beriicksichtigung der Versuche mit dem Mangansulfat - nicht so gross, dass solche gewaltigen Zeitunterschiede lediglich darin ilıren Grund haben könnten; eine wolıl berechiggte Annahme, welche anch bei der Beurtheilung der Resultate mit Nickel- und vor allem aber mit dem Kupfersulfat berücksichtigt werden muss.

Analog dem Zinksulfat sind auch bei den Accommodationsrersuchen gegeniuber dem Kupfersulfat die Resultate der Erwartung entsprechend. Gemäss der einscliäglichen Tabelle der Tab. I brauchten die sporen einer giftfreien Kultur zur Entwickelung auf Concentrationen dieses Salzes von 10, 5 und 2 Litern 21 Tage, auf einer solchen von 1 Liter sogar einen Monat. Ein Vergleich dieser Zeitangaben mit den entsprechenden der Tab. II zeigt deutlich die relativ schuelle und leichte Anpassung des Pilzes an das Kupfergift, indem die obigen Daten hier auf 8,3 und 5 Tage lerabsanken, zudem aber der Zustand des entwickelteu Pilzes dieser Kulturen einen durchaus giinstigeren Eindruck machte.

Anch fïr das Nickelsulfat $\left(\mathrm{NiSO}_{4}\right)$, welches sich in jenen ersten Versuchen als ein relativ sehr stark entwickelungshemmendes Medium erwiesen hatte, machte sich besonders in den hohen Concentrationen die Anpassungsfälngkeit des Pilzes in hohem Grale bemerkbar. Dies zeigte sich zunichst in der absoluten Erweiterung der Wachsthumsgrenzen. Wälırend die Sporen einer giftfreien Kultur (Ta), I) sich nur noch auf einer Concentration von 10 Litern zu entwickeln im Stande waren, zeigten diejenigen eines stufenweise ascommodirten Pilzes diese Fähigkeit noch auf einer zehufach stärkeren, darüber hinans allerdings nicht mehr.

Ansser dieser alısoluten Erweiterung der Concentrationsgrenzen für das Wachsthum des Pilzes zeugten aber die Verkürzung der Zeiträume und die kiäftigere Hyphenentwickelung durchaus dafür, dass der Organismus sich in seinen Lebensfunctionen entsprechend verändert hatte. Bei Sporen einer giftfreien Kultur war die Entwickelung auf einer Concentration von 10 Litern eine äusserst schwache, während die Sporen des accommodirten Pilzes noch bei einer Concentration von 5 Litern zu einer starken und fructifici- 
renden Decke sich entwickelten, und bei einer solchen von 2 Litern zwar nu die Bildung kleiner Tuseln, inmerlin aber die Fructification beobachtet werden kounte, welche letztere bei der sehr hohen r'oncentration von 1 Liter erst ausblieb.

Bei dem schwefelsauren Eisenoxyu $\left(\mathrm{Fe}_{2}\left(\mathrm{SO}_{4}\right)_{3}\right)$ hatten meine Accommodationsversuche nicht den Erwartungen entsprechende Resultate; indem sowohl die Concentrationsgrenzen wie die Zeitrerhältnisse und die Art der Entwickelung annähernd dieselben blieben, ein Umstand, welcher vielleicht in den stark katalytischen Eigenschaften dieses Salzes seinen Grund lıaben kann.

Das Bleinitrat $\left(\mathrm{Pb}\left(\mathrm{NO}_{3}\right)\right.$ ), welches ich wegen seiner dem Eisensalz analogen Wirkung vorweg nehmeu möchte, hatte schon den Sporen einer giftfreien Reinkultur gegenïber eine relativ sehr starke entwickelungshemmende Wirkung gezeigt; dieselben keimten zwar noch auf einer Concentration von 5 Litern aus und entwickelten sich hier zu dïrftigen, submers wachsenden Hyphenbällen; eine Decke aber und Fluctification vermochte der Pilz nul noch anf einer Concentration von 200 Litern zu erreichen. Die Aupassung an den Charalter dieses Salzes schien für den Pilz in Folge jenes hohen Giftigkeitsgl:ides unmögliclı zu sein. Denn obwohl zu diesen Accommodationsversuchen die Sporen jener letzterwiihnten Kultur von 200 Litern melımals auf dasselbe Medium nmgeimpft waren, blieben die Rosultate dennoch dieselben. Dass die starke Giftwirkung dieses Salzes hier sich lediglich als eine entwickelungshemmende erwies, welche der Pilz anch nach einer mehrere Generationen hindurch andauernden Gewöhnumg nicht zu ïherwinden in Stande war; erhellt am klarsten daraus, dass jene submersen Hyphen nach vorsichtiger Tebertragumg in viftereie Nährlösung sofort eine schnelle Weiterentwickelung zeigten, ein Tmstand, welcher von neuem die sehr viel geringere Resistenz der Hyphen gegenüber den Sporen beweist").

Für die folgenden Salze bemerkt man nun beim Tergleich der entsprechenden Reihen der Tabellen der Tab. I und II iu den Resultaten der Versuche durchweg ein mehr ouler minder stark herrortretendes Anpassungsvermögen des Pilzes.

Das schwefelsaure Cadminm $(\mathrm{CdSO})$, welches in einer Concentration von 50 Litern die Eutwickelung der Syoren einer giftfreien $\mathrm{Kultur}$ völlig verhinderte, liess dieselle fuir riejenigen rines 
accommodirten Pilzes noch auf einer Concentration vou 10 Litern zu; beim Kobaltsulfat steigt diess: Grenze von einer Concentration von 100 Litern auf diejenige von 50 Litern, also rund auf das Doppelte. In heiden Fällen war allerdings die Entwickelung eine insserst schwache und erreiehte bei dem ersteren der Salze nicht mehr die Reifeperiode in soleher Concentrationsbïhe, wnraus sich schliessen lässt, dass diese bejiden Salze, wie auch in erlöhtem Maasse die folgerden, im Verglejeh zu dem Zink- und Kupfersalz gegenüber dem Pilze einen erhelılich stïrkeren entwickehugshemmenden Charakter besitzen.

Bei den Versuehen mit den beiden Quecksilbersalzen ( $\mathrm{HgCy}_{2}$ und $\mathrm{HgCl}_{2}$ ) liessen zwar beide, das Cyanid sowohl in der Erweiterung der Concentrationsgrenze für das Wachsthum von 500 Litern auf 50 Litel - also un das Zehnfache! - als auch in der Abkỉrzung der Zeiträume, das Chlorid nu in diesem letzten Punkte die erfolgte Aecommodation des Pilzes an diese heiden starken Gifte deutlich erkennen; immerlnin konnte aber fül das letztere wegen seiner eminenten Giftwirkung einc höhere Concentrationsgrenze nicht erreicht werden. Dieses Urtheil iiber den Grad der entwickelungshemmenden Eigensehaft des" Sublimates, die auch nach gemachten Prohen hier mit einer letalen Wirkung nahezu zusammenfiel, konnte zwar schon aus den Versuchen mit Sporen einer giftfreien Kultur gefällt werden; dennoch blieb es bei diesen Versuchen mit den beiden stark giftigen Verbindungen des Quecksilbers auffallend, dass del Grad der Anpassung an die zwei Salze desselben Metalles seitens des Pilzes nicht entfernt im gleiehen Verlälltuisse steht. Allerdings schien dies nach den vorher gemachten Erfahrungen und den daraus geselı̈̈pften Vermuthungen ${ }^{1}$ ) in der grossen Verschiedenheit des Dissociationsgrades seinen Grund zu haben; nach den Beobachtungen bei Gelegenheit dieser Accommodationsversuche musste mir aber der Cirad der Giftigkeit doèh von der specifischen WVirkung des nicht dissociirten Theiles abhängig erscheinen. 1)enn ein Vergleicb einer Quecksilbercyanidlösung von 50 Litern mit einer Sublimatlösung von 2000 Litern hinsiehtlich der vorhandenen Anzahl activer $\mathrm{Hg}$-Jonen wird zwar nieht die relative, sicherlieh aber die absolute Majorität für die erstere ler Lösungen ergeben. Beruhte demnach die entwickelungshemmende bezw. tödtliche Wirkung lediglich auf derjenigen der 
activen Metall-Jonen. so wäre das so erheblich rerschiedene Terhalten des Pilzes diesen beiden Concentrationeu der beiden Queclisilbersalze gegenüber nicht erklärbar bezw. unbegründet.

Das letzte noch zu erwähnende Salz, das Thalliunsulfat $\left(\mathrm{TI}_{2} \mathrm{SO}_{1}\right)$. musste gemäss den Erfahrungen mit den Sporen von giftereier Kultur mit den Sublimat miudestens auf gleiche Stute gestellt werden; wach den Resultaten dieser letzten Tersuche aber schien der Pilz im Tergleich zum Sublimat für dieses Salz ein grösseres Anpassungsrermögen zu besitzen, indem jene Grenze für die Entwickelung um das Doppelte - von einer Concentration von 2000 Litern auf eine solche vou 1000 Litern - stieg.

Wenm man numuehr einen Rückblick auf die gesammten Resultate dieser Accommodationsversuche wirft, so geht aus ilmen als bewiesen herror, dass ein Schinmelpilz, indem der Organismus sich in seinen Lebensfunctionen an den Charakter des ungebenden Mediums allmählich gewöhnt und diese bis zu einem gewissen Grade zweckentsprechend umgestaltet bezw. ausbildet, durch solche Accommodation sehr wohl befihigt werden kann, durch die erworbene Resistenz ein sehr holes Maass entwickelungshemnender Eintlüsse. wie die rorliegenden Salze im allgemeinen sie besitzen. zu überwinden und damit den Grad der Wirkung solcher Agentien mehr oder weniger, z. Th. ganz erheblich herabzudricken.

Der natülliche und günstigste $\mathrm{ITeg}$ zur Erlangung grösserer Resistenz durch Anpassuug musste für den Pilz der vou mir eingeschlagene sein. d. l. anf dem Uebertragen der Pilzsporen vun Generation zu Generation unit stufenweiser Erhöhnng der Conceutrationen beruhen. Dadurch wurde der Organismus sowohl an den Charakter als auch zugleicl progressiv an die Quantitit des Giftstoffes und die damit zumelinente absolute Giftwirkmg desselben gewölıt. Immerhin kunnte sich nach einigen Beobachtungen. welche iclı nebenher machte, daran die Frage knüpfen lassen, ob niclit schon eine lange Gewöhunng an den Charakter desselben alleiu ohne Berichsichtigung des zweiten Factors, der Quantität also wenn diesellse viele Generationeu hindurch auf niederen Coucentrationen fortgeführt wurde - genügen würde, um dem Pilze für eine Entwickelung auf eirer hohen Concentration olne vorangeheude stufenweise Erhöhung bis zu dieser Stärke, wenn nicht eine gleichwerthige, so doch eine anuähernd gleiche Resistenz zu verleihen. 
In den Tabellen der Tab. II habe ich fast durchgehend zum Tergleiche die Resultate mit Sporen eines Pilzes beigefügt, welcher nur eine Generation hindurch nnd zwar anf einer verhältnissmässig schwachen Concentration des betreffenden Salzes kultivirt war. Allerdings sind diese wenigen Versuche hier nur beilänfige und ohne nähere Beritcksichtigung der osmotischen Druckveränderungen angestellt worden; deunoch aber komnten sie nicht als ganz belanglos relten.

Bei cinigen derselben, z. B. denjenigen mit Nickelsulfat, rersagten solche Sporen von geringen Concentrationen bei einem grö̈seren Sprunge in der Zunalnue des Salzgehaltes völlig; bei den Versuchen mit Kupfersulfat aber zeigten die Sporen eines Pilzes, welcher auf einer Concentration von 200 Litern kultivirt war, wie aus der Vergleichstabelle ersichthch ist, schon nach ein er Generation den Sporen einer giftfreien Kultur gegenüber bei einer plötzlichen Erböhung auf 10 und 5 Liter durch die Abkürzung der Zeitrïume eine uuverhältnissmässig grosse Znnahme in der Resistenz.

\begin{tabular}{|c|c|c|c|c|}
\hline $\begin{array}{l}\text { Inzahl der Litel, in } \\
\text { denen } 1 \text { Trammmolekîl } \\
\text { geröst ist }\end{array}$ & Pilzspóren rou & $\begin{array}{l}\text { Sichtbare } \\
\text { Keimung }\end{array}$ & Decke & Fructification \\
\hline 111 & lieinkultur & nach 21 Tagen & Dach 2 Honaten & nach 3 Mnoaten \\
\hline 111 & 200 Lit. & "11) & maclı 16 Tagen & nach is Tagen \\
\hline$\vdots$ & leinkultur & "21 " & mach 2 Iluuaten & nach 3 Monaten \\
\hline & 200 Tit. & " $16 \%$ & nach 21 Tagen & nach 28 Tagen \\
\hline
\end{tabular}

Un aber diese Frage iiber den Unterschied einer lediglich auf den Charakter des Giftes gerichteten Accommodation gegeniiber einer stufenweise, parallel zur Concentrationssteigerung ansteigenden $z u$ entscheiden, war es nöthig, eingehendere und genauere Tersuche anzustellen und vor allem den Einfluss osmotischer Druckmnterschiede zu eliminiren, so dass lediglich die Wirkung des Metallgiftes als solches zur Geltung kam, da anch kleine Zeitunterschiede hier bei der Beurtheilung vou Wichtigkeit waren. Es musste somit mit isotonischen Lösungen gearbeitet werden; da solche aber anch im weiteren Verlaufe meiner Arbeiten mit Kupfersulfat zur Verwendung kommen mussten, so will ich vorweg noch einige kurze Mittheilungen ïber die wenigen Versuche geben, welche ich angestellt lratte, um der bereits erwähnten Frage näher zu treten: 


\section{Verleiht die durch Accommodation erworbene Resistenz gegen das eine Metallgift dem Pilz auch eine relative Unempfindlichkeit gegen ein anderes?}

Zwar war es nicht zu erwarten, dass die durch Accommorlation 'rworbene erhöhte Resistenz bezw. die diese bedingende Verånderumg der Lebensfunctionen des Pilzes so allgemeiner Natur seiu wïrden, dass die Sporen eines an ein bestimmtes Metallsalz der gewihlten Serie accommodirten Pilzes die dadurch erworbene Eigenschaft grösserer Resistenz für dieses eine auch gegenïber jedem anderen Gliede derselben in entsprechender Concentration zeigen wïrde ${ }^{1}$ ). Immerhin aber konnte diese einmal erworbene Eigenschaft sich mit Rücksicht auf die chemischen Analogien einiger der betreffenden Metallgifte für eine Gruppe als gleichwerthig heransstellen.

Um diese Vermuthung zu prüfen, wurden die Versuche in der Weise angestellt, dass Sporen eines auf der einen oder andern Metallsalzlösung mehrere Generationen hindurch kultivirten, an dieses Medimm also stark accommodirten, Pilzes auf die gleiche Concentration eines der andern Metallsalze und vice versa übertragen wurden. Dia die Concentrationen mit den Ausnahmen, wo die zu impfenden Lösungen wegen ilnes Giftigkeitsgrades procentualisch schwächer waren, als molekulare Lösungen die gleiche Stärke besassen, so konnten zeitliche Verschiebungen in Folge osmotischer Druckunterschiede die Resultate nur wenig oder in jenen Ansuahmefällen nur relativ giinstig beeinflussen.

In den gemäss den Resultaten dieser Versuche aufgestellten Tabellen der Tab. III bezeichnen die in der dritten Vertikalreihe befindlichen Angaben eimmal das betreffende Salz, an welches der Pilz accommodirt, und die darunter stehende Zahl in Litern jeweils die Höhe der Concentration, auf welcher die letzte Generation kultivirt war. Es sei wohl bemerkt, dass die hier verwendoten Sporen ausnalimslos den entsprechenden Kulturen der Tab. IT entstammten. somit also den dort verzeichneten Maximalgrad der Aupassumg erreicht latten.

Tergleicht man numehr die Resultate der eiuzelneu Tabellen dieser Tab. III mit denen der Tab. I und II - ich habe die entsprechenden Daten als Parallelaugabeu zur leichtereu I ebersicht 
in den Tabellen der 'Tab. III aufgenommen — so wird man findes, dass zwischen der Anpassung des Pilzes an das Kupiel- und Zinksulfat und damit in den Charakter dieser Salze beziiglich ihrer physiologischen Wirkung gegenüber diesem Pilze eine gewisse Analogie zn herrschen scheint. Denn gegeniiber len Sporen einer giftreicn Reinkultur orschienen diejenigen eines an Kupfersulfat accommodirten Pilzes entschieden - auch unter Bericksichtigung der osmotischen Drnckverhältnisse - fïr die Entwickelung auf einer äquimolecularen Zinksulfatlösung geeigneter und vice versa.

Desgleichen zeigten Sporen eines an diese beiden Salze accommodirten Pilzes denjenigen einer giftfreien Kultur gegeniber auch bezüglich der Futwickelung auf Lösungen von Nickel-, Cadmiumsulfat und Quecksilbercyanid eine grössere Resistenz. Hinsichtlich der TVeiterentwickelung auf einel Cadmiunsulfatlösung schien die Anpassung an jene Salze sogar einen grünstigeren Effect auf den Pilz gelıabt zu haben, als diejenige an das gleiche Metallsalz $\left(\mathrm{CdSO}_{1}\right)$, inden die Grenze für die Fructification bei jenen Versuchen - auch in zwei Wiederholungsfällen - zurickblieb, eiu Umstand, welcher von den veränderten osmotischen Druckverhältnissen sicherlich völlig unabhängig war.

Mit den Sporen eines an Nickelsulfat accommodirten Pilzes und bei sämmtlichen Versuchen mit Cobaltsulfat konnte ich analoge Resultate, wie die obigen, nicht erzielen. Das Cobalt ist vom chemischen und physikalischen Standpunkt aus betrachtet ein dem Nickel ungemein ähnliches Metall; eine etwaige analoge Verwandtschaft dieser Metalle hinsichtlich ihrer physiologischen Wirkung ist wohl bis jetzt weniger genau studirt worden. Ol, eine solche iiberhaupt besteht, muss dahin gestellt lıleiben; für meines Pilz schien sie jedenfials nicht vorzuliegen, denn die Sporen eines an das Nickelsulfat immerhin relativ stark accommodirten Pilzes liessen liei einem Austausclı, dieses Salzes gegen das Cobaltsulfat irgendwelche Anzeichen einer durch Anpassung erworbenen, grösseren Resistenz füi dieses letztere in keiner. Weise erkennen.

Nach den Ergehniss dieser gesammten Versuche erscheint zwar, gestiitat auf einige Resultate, wie diejenigen mit dem Kupfer- und Zinksulfat, die Möglichkeit der Annahme einer Aelnnlichkeit in der physiologischen Einwirkung auf den Organismus des Pilzes für einige Metallsalze nicht ganz unberechtigt; immerhin aber kann man directe Schluisse auf eine ganz oder theilweis generelle Natur der Accommodation, beziehungsweise der durch dieselbe erworbenen 
Eigenschatten, wie sie durch jene Analogie in der plysiologrischen Wirkung fiir diese beiden Salze begründet sein könnte. so lange nicht ziehen; bis die Frage duch eingehendere Versuche noch meh* aufgehellt ist.

Nach diesen Mittheilungen der wenigen, vom eigentlichen Thema meiner Arbeit etwas abschweifenden Versuche. komme ich zu der fiir die Art der Accommodation wichtige und bereits oben angedeutete Frage zuriick:

\section{Wie verhalten sich die Sporen eines melirere Generationen hin- durch auf gleichen schwachen Metallsalzlösungen kultivirten Pilzes gegenüber denen eines stufenweise mit allmählichem Steigen des Salzgehaltes von Generation zu Generation an das Gift accommo- dirten?}

Es war schon aus einigen beiläufigen Versuchen ${ }^{1}$ ) erkenubar geworden, dass mit einigen Ansnahmen die Sporen eines auf einer verlialtnissmässig nur schwachen Metallsalzlösung kultivirten Pilzes - am augenfälligsten bei dem Kupfersulfat - sich dennoch ganz unverhältnissmässig bessel zur Eutwickelung auf einer selır hohen Concentration gleicher Art - im Vergleich zu den Versuchen eines bis zu jener Grenze stufenweise accommodirten Pilzes eigneten, als die Sporen einer giftfreien Ḱultur.

Wem somit schun die Anpassung an die physiologischen Einwirkungen des Giftes anf den Organismus - also an seine specifischen Eigenschaften für den Pilz, welche ich in diesem Sinne kurz als seinen "Charakter" bezeichnen möchte —, neben derjenigen an die Quantität und die damit absolut zunehmende Giftwirkung desselben eine so auffallend grosse Rolle in der Frage der Accommodation zu spielen schien, su konnte man nach den gemachten Esfahrungen iiber die progressive Zunahme del Resistenz mit dem Grade des Generationen wohl vermuthen, dass auch ohne stufenweise Erhöhung der Concentrationen der Pilz auf schwachen Iösungen nach und mach auch einen sehr hohen Grad von Resistenz gegen das Gift, anch in hohen Dosen, erwerben wïrde.

Weges des umfangreichen Materiales habe ich these und die жur Erledigung der noch folgenden Fragen angestellten V'ersuche 
lediglich auf das Kupfersalz beschriinkt. zumal ja olne weiteres wolıl angenommen werden kam, dass die Resultate fiil jedes andere der Salze analoge sein werden.

Zur Erlangmg genauer Resultate in den Zeiträmmen war es hier: wie bereits erwihnt, vor allem erforderlich. den Hinfluss usmotischer Druckuntersebiede, die hier auftreten mussten, auf die zeitliche Fntwickelung der Sporen, so weit als mighich, zu eliminiren; es musste alsu mit isotunischen Lösmgen gearbeitet werden.

\section{Herstellung der isotonischen Lösungen.}

In den zu den weiteren Versuchen der Arbeit nothwendigen lösmngen wurle die IJebereinstimmung des osmotischen Druckes

Fimur 1.

lisooriationsuefficienten.

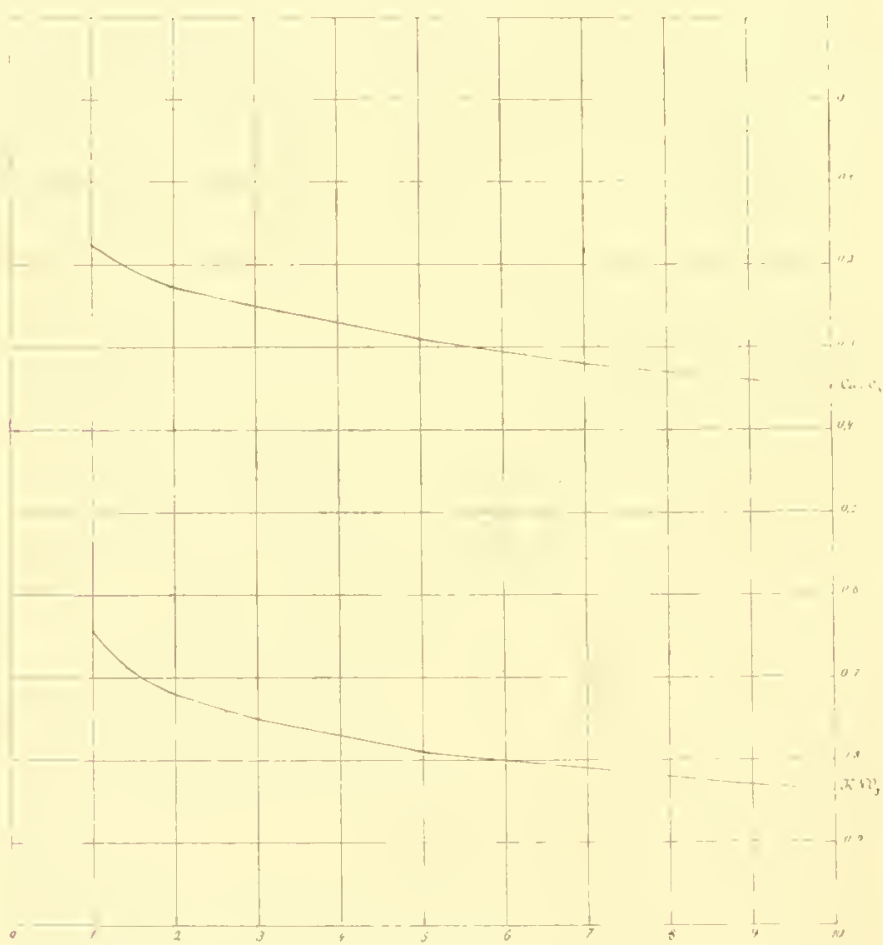

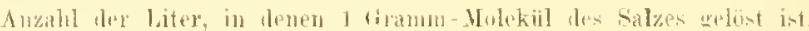

dadurch erreicht, dass bei geringem Gehalt an Kupfersulfat (z. B. 200 Liter) der gegenüber einer holnen Concentrition dieses Salzes (z. B. 10, 5 oder 2 Liter) bestehende Druckunterschied durch 
einen entsprechenden Zusatz des fiir die Entwickelung des Pilzes indifferenten Salzes. des Kalisalpeters, ansgeglichen wurde. Der usmotische Druck der betreffenden Kupfersulfatlösung war aber nicht allgemein bekannt; ferner aber bot wegen der starken tödtlichen Wirkung dieses Salzes zumal auf höheren Concentrationen ${ }^{1}$ ) einerseits, andrerseits in Folge der geringen Grösse der Hyphen des I'enicillinm glaucnm eine Bestimumug anf plasmolytischem $T$ ege nicht unerhebliche Schwierigkeiten.

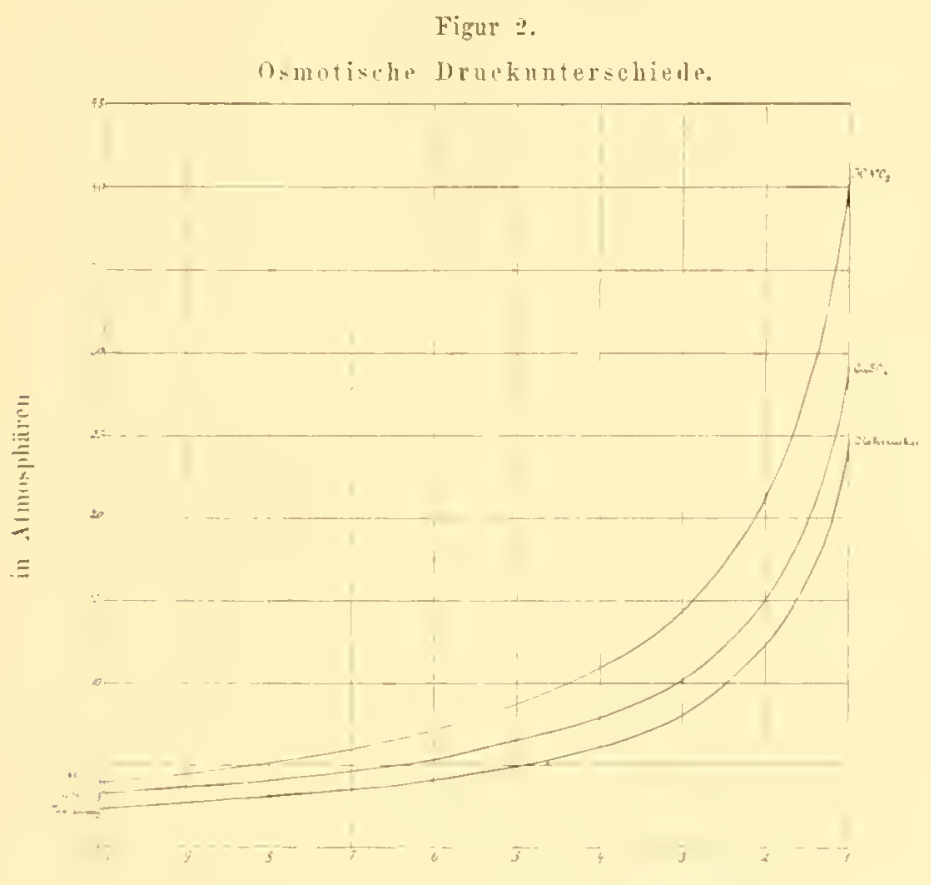

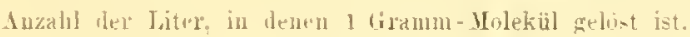

Da nun eine wïsserige Kupfersulfat- und Kaliumnitratlösung, wie erfahrungsgemäss auch die der meisten Metallsalze, eine theilweise Dissociation der Moleküle erfahren. und der osmotische Druck mit diesem Vorgange in engem Zusammenhange stelıt, so ist man in der Lage: aus dem jeweiligen Dissotiationscuefficienten soleher Salzlösnngen, die durch diesen chemisch-physikalischen Vorgang bedingte Druckerhöhung gegeniiber dem bekannten usmotischen

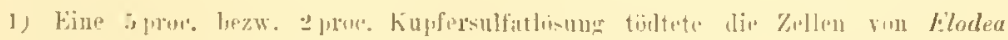
canadensis in wenieren incunden. 
Drucke einer gleich concentrirten Rohrzuckerlösung ${ }^{1 j}$ zu ermitteln ${ }^{2}$ ).

Die auf diesem IVege ermittelten Resultate sind durch die betreffenden Curven (p. 35) dargestellt, welcher ich anch noch eine solche für die Dissuciationscoefficienten (p. 34), aus welchen jene berechnet wurden. beigef ügt habe.

Aus praktischen Grinden habe ich durchgehend für sämmtliche Knlturen dieser Versuche den einheitlichen osmotischen Druck ciner Kupfersulfatlösung ron ¿ Litern gewählt. Die Berechumug der erforderlichen Menge des zuzusetzendeu Salpeters wird damn für relativ geringere Concentrationen des Kupfersalzes an der Hand der einschläglichen Curve folgendermassen zu machen sein:

Eine Concentration von 200 Litern $\left(\mathrm{CuSO}_{4}\right)$ labe ich wegen der sehr geringen Druckerhöhung wie eine kupfersalzfreie Nöhılösung behanclelt; anders für die Concentration von 10 Ijitern und 5 Litern!

Gemaiss der Curre betrïgt:

der osmot. Druck einer Kupfersulfatlösung 2 Lit. 15,16 Atm.

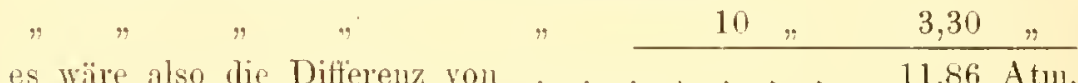
durch den diesem Drucke entsprechenden /usatz von rund $3^{0}$ o Salpeter auszugleichen.

Allerdings findet bei einer derartigen Combination zweier wässeriger Salzlösungen eine theilweise, wechselseitige chemische Umsetzung und ladurch auch eine Veräıderung der physikalischen

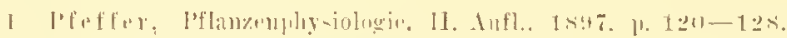

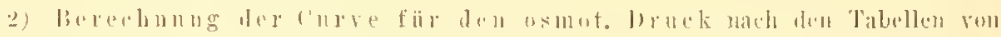

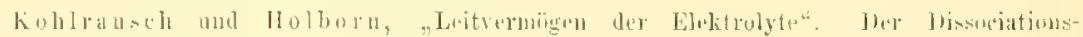

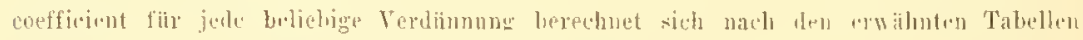
für las Leitrermeigen der Elektrolyte niteh dor Formen:

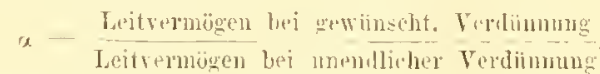

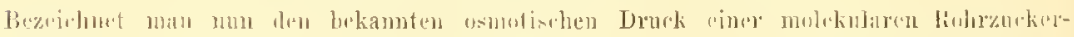

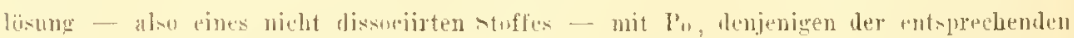

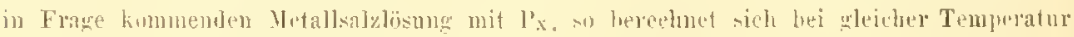

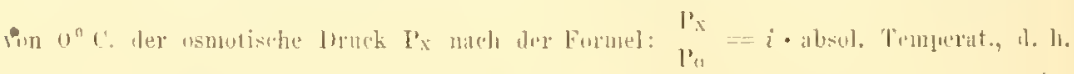

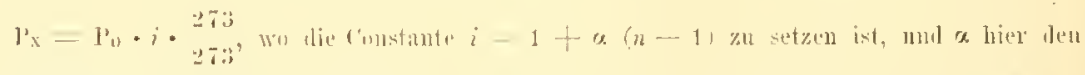

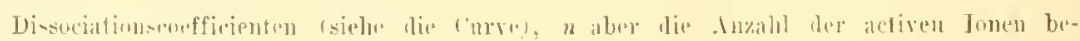
zoichnet. 
Verhïltnisse statt; doch ist dieselbe nicht so weitgehend, dass sie für die rorliegenden Untersuchungen besondere Beriicksichtigung verdient.

Der analogen obigen Berechuung entsprechend bedurfte eine Kupfersulfatlösung von 5 Litern eines Salpeter-Zusatzas von $2,2^{\circ}$, un mit einer solchen von 2 Litern isotonisch zu sein.

Mit solchen in dieser beschriehenen Weise hergestellten isotonischen Lösungen, wie sie für meinen Zweck genügten, wurden nun zumächst die Versuche über die Art der Accommodation und ihre stufenweise Zunahme vorgenommen, welche in den Resnltater der Tab. IV ihren Ausdruck finden.

Dabei stellte sich nun, wie das zu erwarten war, gemäss den Daten der Horizontalreihe 1 und 2 bezw. 5 und 6 herans, dass bei einer Impfung auf eine Kupfersulfatlissung von 5 bezw. 2 Litern Sporen eines fünf Generationen hindurch auf einer Kupferlösung ron 200 Litern kultivirten Pilzes sowohl in der Abkiirzung der Zeiträume als auch durch eine kräftigere Entwickelung einen zweifellos höheren Grad der Resistenz, als Accommodationseffect, zeigten als solche von einem Pilze, welcher nur eine Generation hindurch auf dem gleichen Medium ( $\mathrm{CuSo}_{+} 200 \mathrm{Lit}$.) gewachsen war.

Eine Concentrationserhöhnng ron 200 Liter'n auf 5 bezw. 2 Liter ist eine ausserordentlich grusse und damit die Erhöhung der Quantitüit des wirksamen Giftes eine ganz erhebliche; wenn also dennoch eine Zunabme der Resistenz bezw. der Entwickelungsfähigkeit der Sporen auf diesem Giftmedium durch diese Art der Anpassung festgestellt werden lionnte, so komnte diese nur durch eine linge anlialtende Gewöhnung ausschliesslich an den „Cluaraliter" les Giftes erzielt worden sein.

Die weiteren Daten der Tab. IV geben die Resultate einiger Parallelversuche zu den obigen und sollen einen Anhalt für die Beurtheilung jener Art der Accommodation gegenïber einer solchen mit stufenweiser Erhöhung des Giftgehaltes bilden. Wenn num darnach die Erwerbung grö̈sserer Resistenz aut' jenem Wege zweifellos unverkennbar ist. so scheint allerdings dennoch - wie es ja auch den sonstigen Erfahnnugen auf anderen Gebieten entspricht - der gleiche bezw. ein lresserer Effect in bedeutend kürerer Zeit dureh ein stufenweises Vorgehen (Horizontalreilıe 3 und 7) rrreichbar zu sein. 
Dass bei jener ersten Art der Accommodation durch eme alusserordentliche Vermehrung der Anzahl der Generationen die Resistenz des Pilzes noch erhehlich verstärkt werden wird, ist nach diesen Erfahrungen zweifellos anzunehmen; ob aer Effect aber schliesslich ein gleicher werden wird, wie bei einem stufenweisen Vorgehen, und damit lediglich die Aupassung an den Charaktel des Giftes in Frage kommt, muss bislang noch dahingestellt bleiben.

Immerhiu aber wird diesen Erfahrungen gemäss der Maximaleffect der Accumnodation durch eine Bericksichtigung beider Factoren gewährleistet sein, wie dies schon an den Resultaten der Horizontalreihen 4 und 8 sich zeigt.

Es wird somit anch in solcher Höhe der Coucentration mit ler wachsenden Anzahl der Generationen die Widerstandsfähigkeit hezw. der Grad der Accommodation noch gan\% erhoblich zunehmen, wem nicht dadurch sogar vielleicht ein gewisser Grad von Bevorzugung dieses Mediums seitens des Pilzes erreicht wird, welcher fiir denselben las lietreffende Gift schliesslich als ein Existenzbediufniss elscheinen lassen könnte.

Un die Richtigkeit dieser Vermuthung zu priifen, wurden die Versuclıe angestellt, deren Resultate in der Tabello A der Tab. V anfgezeiclnet sind.

Dieselben bestanden darnach in zwei Reihen von Parallelkulturen. indem die Sporen eines Pilzes, welcher vier Generationeu hindurch auf kupferhaltigem Nährboden - und zwar in den letzten beiden auf einer Coucentration von 5 Litem - kultivirt war, einnal auf ein mit diesen völlig identisches Medium (Reihe 1), zum audern aber auf eine isotonischo giftfreie Nïhrlösung (Reihe 2) iibertragen wurden.

War die Vermuthung richtig, so hätte - wie min erwarten musste - die Entwickelung solcher Sporen auf dem gleichen, kupferhaltigen Nïlnuedium nicht nur eine bessere als auf dem kupferfreien, sondern - in giinstigsten Falle -.. hätte diejenige anf dem kupferfreien Mediun gegeniiber der Entwickelung „nicht accommodirter" Sporen, also gegeniiber den Sporen von einer giftfreicn Reinkultur, eine relativ schlechtere sein missen. Diese Erwartung wurde aber, wie aus den Daten hervorgeht, getäuscht; vielmehr liess die schuellere und kräftigere Fntwickelung solcher Sporen eines an Kupfer stark accommodirten Pilzes auf dem giftfreien Niblnmedium darauf schliessen, dass auch dieser Pilz die 
natiolichen, numalen Verhailtuisse bevorzugte. in welche er aus einem pathologischen Lustande zuriiclikehrte.

Nach dieser Schlussfulgerung war es naheliegend, dass ich bei der Frage nach der Danur der durch Accummodation erworbenen Figenschaft zu einer negativen Beantwortung wiirde gelangen miissen.

\section{Ist die durch Anpassung erworbene Eigenschaft des Pilzes eine vorübergehende oder wird sie zu einer bleibenden; so dass man geneigt sein könnte, von einer Vererbung zu sprechen?}

Durch die vorigen Versuche war zwar bewiesen, dass die Sporen eines an Kupfersulfat gewöhnten Pilzes dennoch das giftfreie Medium bevolzugten. andrerseits aber ist in gleicher Weise die dureh Accommodation gesteigerte Entwickelungsfäligkeit solcher. Sporen auf demselben Giftmedium aus den fruheren Versuchen deutlich erkennbar geworden. Da mu die eine Thatsache die audere nicht nothwendigerweise ausschliesst, so war die Frage immerhin berechtigt. ob iene erworbene Eigenschaft solcher Sporen völlig erlischt, sobald dieselben, bezw. der daraus sich entwickehde Pilz eine oder melrere Generationen hindureh auf eineus giftfreien Nährmedinm - das jene ja bevorzugten - kultivirt wal, oder ol sie eine fiir immer bleibende, also "erblich" geworden war.

/wecks Beantwortung dieser Flage wurden zunächst die Sporen der in der Horizontalreihe 1 der Tab. VA verzeichneten Kultur, also von einem 5 Generationen hindurch an das Kupfersalz gewölnten Pilze, füı eine; zwei und drei Generationen auf einer mit der Kupfersulfatlösung ron 5 Litern isotonischen, giftfreien Nährlüsung kultivirt.

Die Spporen dieser so angestellten Kulturen wurden nun in der Reilienfolge, wie sie in der ersten Vertikalreihe der Tab. V B verzeichnet sint. neben denjenigen einer gewöhnlichen isotonisehen Reinkultur - als Parallele — jeweils auf eine Kupfersulfatlösung von 5 Litern ibertragen.

Da alle Lösungen nit der zu impfenden isotonisch waren, so konnte ein Zeituntersehied nur mit der erhaltenen Wirkung der vorher elfolgten Anpassung an das Gift in Zusammenlang gebracht werden. Wie aber die Daten dieser Tabellen beweisen, stellte sich nun heraus. dass der Pilz die durch Aeenmmodation erworbene Eigenschaft gröisserer Resistenz- und Entwickelungsfilngkeit für das 
gleiche Medium amuähernd in demselben Maasse verliert, wie sie gewonnen wurde; dem die Daten der Reihen 1 nnd 4 stimmen schon nahezu ïberein.

Unschwer konnte der Einwurf gemacht werden, dass nach einer etwa 100 bis 500 Generationen hindurch erfolgten Accommodation des Pilzes die Versuche sehr wohl andere und zwar in Sinne der Erblichkeit günstigere Resultate ergeben würden. Mit gleichem Rechte aber kamn man wohl als nicht ausgeschlossen annehmen, dass diese Fühigkeit danı bei entsprechender Entwöhnung nach ebenso viel Generationen wieder in gleicher Weise verloren würde. Diese Frage kann jedoch ohne die entsprechenden Versuche, zu deren Anstellung wegen der erforderliehen grossen Anzahl derselben die für die Gesammtarbeit bemessene Zeit nicht ansreichte, end. giltig nicht entsehieden werden.

Im Anschluss an diese Resultate meiner gesammten Arbeiten hatte ich es mir num noch zur Aufgabe gemacht, einige Versuche anzustellen, welehe dem Ziele zusteuern, einen Einblick zu gewimen in die Ursache dieser aussergewöhnlichen Fähigkeit der Schimmelpilze, insunderbeit eines P'enicillium glancum, auf so boch concentrirten bezw. so stark giftigen Metallsalzlösungen zı gedeihen. Die nätchstliegende, fiir weitere Forschungen in diesem Sinne wohl maassgebende und taher wiehtigste Frage betrifft dann wohl das Eindringen des Metallgiftes in die Zelle ${ }^{1}$ ), bezw. die Aufnalme des Metalles in irgend einer Form.

Dieser Frage bin ich bestrebt gewesen, so weit es mir möglich war, durch die folgenden Versuche gerecht zu werden.

\section{Dringt die CuS0,-Lösung in das Protoplasma des Pilzes ein, bezw. wird das Metall von dem Pilze aufgenommen?}

Die Möglichkeit einer positiven Beantwortung dieser Prage konnte mach den reichhaltigen Erfahrungen ïber die Aufnahme mehr oder weniger giftiger Stoffe dureh die Zelle nicht ohne weiteres für ansgeschlossen gelten.

Bei einem kurzen Ueberblick üher die diesbezüglichen Arbeiten,

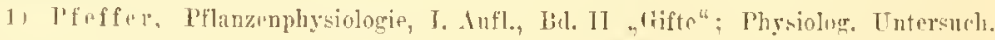

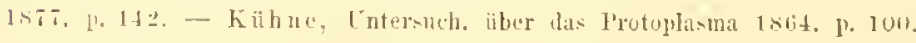


wie ihn Pfeffer ${ }^{1}$ ) in seinem Abschnitt iiber die entbelnlichen Aschenbestandtleile der Pflanzen giebt, muss man die Resultate dahinzusanmenfassen, dass mit wenigen Ausuahmen, die vielleicht nur amf das seltene Vorkommen des betreffenden Metalles in der oberen Erdschicht zurückzufülıren sind, fast sämmtliche Metalle in den Aschen phanerogamer Pflanzen in mehr oder weniger grossen Mengen gefunden worden sind.

Wie verhält sich nun Penicillium glaucnm zu der Aufnahme solcher Metalle, bezw. zu dem Eindringen der Lösung solcher Metallsalze, von denen ich nur das Kupfersulfat einer genauen Untersuchung unterworfen habe, da wohl anzunehmen ist, dass bei den analogen Wachsthumsresultaten auf den andern Metallsalzlösungen sich auch das Verhalten des Protoplasma im wesentlichen sleich gestalten wird?

Da es sich nun zunächst mur darum handelte testzustellen, ob eine Anfnahne des Metalles iiberhaupt stattfand, olne Riicksicht auf die Form und den Ort. so musste der Nachweis als Aschenbestandtheil, den ich mittelst Schwefelwasserstoff' anstellte, rorerst genügen. Um aber einen solchen auf diesem Wege zu ermöglichen, walr es nothwendig. die auf Kupfersulfatlösung kultivirten Decken von den iusserlich anhaftenden Rückstïnden jener kupferhaltigen Nälnrlösung durch Abwaschen zu befreien. Da bei einem derartigen Waschen mit destillirtem Wasser in Folge les osmotisclıen Druckunterschiedes ein Absterben der Pilzzellen zu befürchten war, so musste zu diesem Zwecke cine indifferente Lösung verwendet werden - in diesem Falle wude Salpeter dazu verwendet -, welche der urspriinglichen Kulturfliissigkeit mindestens isotonisch war.

Nit dieser Kalisalpeterlösung ${ }^{2}$ ) wurde nun die vorlher in Stiicke gerissene Pilzdecke in einer Kochflasche so lange durch vorsichtiges Schütteln abgewaschen, bis die ablaufende Waschllïssigkeit auf Zusatz von Kaliumferrocyanidlösung eine Kupferreaction nicht mehr erkennen liess. Die abgewischene Decke wurde solann nach schnellem, möglicbst vollständigem Ablaufen der Waschfliissigkeit in einer tarirten Porzellanschale bei $100^{\circ} \mathrm{C}$ im Trockenschrank getrocknet, das Gewicht der Trockensubstanz festgestellt und diese

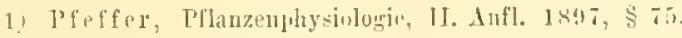

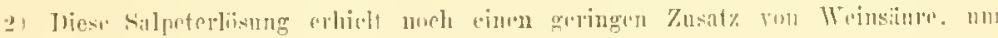

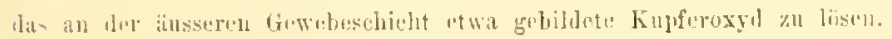


pudlich unter Yusatz, ron chlorsauren Kali und Silzsiure in einem Kolben gekrocht. War die organische Sulsstanz völlig zerstört, so filtrirte ich ab, wasch den Rückstand mittelst destillirten Wassers melsfach nach und leitete in die vereinigten Filtrate nach entsprecliendem Mbstmupfen der Silure und Verjasen des freien Chlor Schwefelwasserstoff in [Teberschusse ein.

Der entstandene Niederschlay vou Cus wurle in der ïblichen Wrise gewichtsanalytisch bestimmt.

/war konnte diese Trockensulsstanz nicht ganz frei von Salpeter sein, der ans der Waschflissigkeit stammte; denn wenn dieselbe auch nach Möglichkeit ablief, so enthielt democh das Adhitsions- und Imbibitionswasser einen Theil gelöst. Diese Mengen aber konnter nicht so gross sein, dass die Werthe fiu das Jeckengewicht sich dadurch wesenthich verschieben mussten. Ich habe dahel diesen Factor bei der Berechnung unberücksichtigt gelassen.

Dieser Kupfernachweis wurle nun fiir 6 Pilzlecken narl]eimander geliefert, ron denen 3 auf einer Kupfersulfatlösung von $2,5 \%$, die andern auf einer solchen von $6 \%$ gewachsen waren. Und zwar ergab die Analyse bei:

den ersten 3 Decken einen Durchschnitssgehalt vou 0,017 Cus für 6 Gramm Trockensubstanz,

den andern 3 Decken einen solchen von $0,02 \mathrm{CuS}$

fǜ 8,5 Gramm Trockensubstanz.

Nimmt man für eine normale, frische Pilzdecke einen Wassergehalt von $80 \%$ an, so berechnen sich daraus:

0,017 CuS für 30,0 Frischsulustanz, d. h. 0,056\%,

0,02 CuS für 42,5 Frischsulıstanz, d. h. $0,05 \%$

Diese Resultate entsprachen aber den Erwartungen nicht; vielmelır ljewiesen sie, dass, ganz alogesehen von einer etwaigen Anfnahme grösserer Mengen, anch ein Endosmiren der Salzlösung in ihrer vollen procentualen Stärke in das Protoplasma selbst, also isosmotisch wenigstens, nicht stattgefunden haben konnte. Denn wäre dies der Fall gewesen, so entsprïchen den obigen Wasserverlust von 24 Gramm bei einer 2,5 proc. Kupfersulfatlösıng amähernd 0,5 Gramm $\mathrm{CuSO}_{1}$, $\mathbf{1}$. 1. ein Idealbefund von von 0,3 Gramm CuS gegenüber dem thatsächlichen von 0,017 Gramm, andrerseits dem Wasserverlust von 34 Gramm bei einer 6 proc. Kupfersulfatlïsung annähernd 2 Gramm CuSO $\mathrm{C}_{1}$, d. Һ. ein ldealbefund von 1,2 (xramm CuS gegenibber dem thatsïchlichen vol1 0,12 Gramm. 
Im ersten Falle blieb der Realbefund also rund un das 20 fache, im zweiten - wbwohl es die concentrirteren Lösmngen waren - sogar $11 m$ das 60 fache zuriick. Ein isosmotisches Eindringen der Giftlösung schien demnach nicht stattgefunden zu haben; es wirk der Pilz also die erforderliche Herstellung des osmotischen Gleichgewichtes mit dem äusseren Metallgift enthaltenden Nährmedium, wje vielfach bei Kulturen auf concentrirten Lösungen ${ }^{1}$ ), durch entsprechende Concentration der Lösungen im Imern der Zelle bewirkt haben. Ein Austreten des Kupfersalzes aus der lebenden Zelle - soferm das Metall iiberhaupt in einer löshichen und endosmirenden Eorm anfgenommen war -- während des Waschprocesses musste aber mit Riicksicht auf die überisotonische WaschHiissigkeit und die zeitliche Kürze des T'erfahrens als nahezu ausgeschlossen gelten.

Woher kan nun der Gehalt an Kinpter in len Aschen?

Wenn nan vorläufig ron der Müglichkeit einer thatsächlichen Aufnalıme des Metalles bis zu einer begrenzten, kleinen Menge seitens des lebenden Protoplasma absieht - dieser Frage bin ich später näher getreten - so waren drei Lösungen für diese Frage vorhanden.

Erstens konnte die Kupfersulfatlösung capillar, also mechanisch, so festgehalten sein, dass es mit Riicksicht auf das Leben der Pilzfïden unmöglich war, diese zwischen dem engen Gewebe der" selben haftende Fliissigkeit gïnzlich herauszuwaschen.

Zweitens aber konnte, wenn nicht die lebende, so doch die abgestorbene Zelle den Kupfergehalt veranlasst haben. Das Absterben einer grossen Anzahl ron Zellen ist ja bei dieser Handhabung des Auswaschens durch wiederholtes Schïtteln unvermeidlich, abgesehen davon, dass es theilweise auch während der Daner der Kultur selist aus verschiedenen Ursachen erfolgt sein konnte. Im Augenblicke des Absterbens aber, wenn vorher eine Permeabilität fuir das Kupfersalz niclıt vorlag, dringt dieses in den Protoplasten ein und könnte hier sehr wohl, bevor eine völlige Coagnlirung stattindet, als Eiweissverbindung in geringer Menge fixirt werden ${ }^{2}$ ).

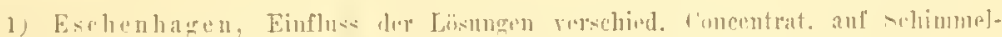

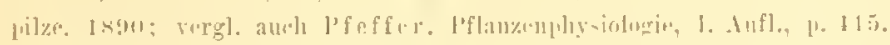

$\Rightarrow$ Loew. (iftwirkungen, ]. !?. 
Endlich aber konnte das Protoplasma mit Riicksicht auf seine Existenz organische Stoffe ausscheiden, welche durch Herstellung unlöslicher Verbindungen ein Endosmiren des Giftstoffes mun̈̈glich machten. In diesem Ealle konnten solclie, der Plasmahaut äusserlich, mechaniselı anhaftenden Rückständen in Folge ihre. Tnlöslichkeit in der. Waschflïssigkeit - obwolıl diese nit Weinsäure angesänert war — den Befund in der Asche wohl bewirkt haben.

Gestiitzt auf das Resultat der Analyse und diese Vermuthungen muss man zwar der Ansicht zmeigen, dass - ganz abgesehen von einem isosmotischen Eindringen der Lösung -_ selbst anch eine Aufnalume nemnenswerther Mengen des Metalles nicht stattfindet. Damit war aber jmmerhin die Frage iber die Anfuahme einer begremzten kleinen Menge des Metalles im Protoplasten noeh nicht entschieden.

Wenu eine solche stattfand, so musste zunäclist vor allen eine Permeabilitit der Plasmaluaut für dieses Metallsalz vorliegen.

Nach den Tersuchen von Klemm ${ }^{5}$ ) drang eine Kupfersulfatlisung bis zu 100: schnell und schadlos in die Vatenolen einger phanerogamer Pflanzen ein, so dass es ihm gelang, diesen Vorgang mittelst eines Zusatzes von Ammoniaklösung durch Blaufürloung in den Protoplasmavacuolen mikrochemisch nachzuweisen. Wegen der unendlich geringen Menge des etwaigen Kupfersalzgehaltes in dem geringen Raume ener Vacuole der Pilzzelle ist es mir leider. trotz wiederholter Versuche nicht gelungen, die Anwesenheit des Kupfers und damit das Endosmiren desselben in die Zelle weder dureh Zusatz von Ammoniak- nocl von Ferrokaliumeyanidlösung mikrochemisch unwiderlegbar nachzuweisen.

Durch die negativen Resultate auf diesem Wege habe ich mich sehliesslich reranlasst gesehen, der Frage der Permeabihtät der Plasmahaut einer Schimmelpilzzelle fïr das Kupfersulfat durch plasmolytische Tersuche näluer zu treten. Dies geselıal in der Weise, dass nebeneinander parallel Zellen eines auf giftfreier Nälılösung kultivirten Pilzes einmal mittelst einer Kalisalpeterlösung, zum anderu mittelst einer isotonischen äquimolekularen Kupfersulfatlösung, welchen beiden etwas Anihinblan beigefügt war, plasmolysirt wurden.

Die Plasmolyse trat bei beiden Versuchsreihen zu annälıernd gleicher /eit ein und ging hei der ersten nach etwa einer Stunde

1) Klann, lesoryanisation der Kellu. 
röllig zurück. Bei der Plasmolyse mit der Kupfersulfatlösung aber war dieselbe auch nach $1^{1}$ ․ Stunde nocls im allgemeinen deutlich erkennbar. jedoch nur an einer verhältuissmässig geriugen Anzahl ron Zellen, da die grössere Menge derselben durch dic eingetretene Blaufärbung im Inneren das Absterben bezw. den schon eingetretenen Torl erkennen liess. Die analogen Tersuche mit den Hyphen eines an Kupfersulfat accommodirten Pilzes ergaben die gleichen Resultate. es trat das Absterben nur entsprechend später ein.

Somit musste nacl dem Ergebniss dieser Tersuche die Permeabilitiit der Plasmahaut für dieses Gift ${ }^{1}$ ) mindestens in Frage gestellt werden, da die Plasmolrse der Zellen mit der Zeit hätte zurücligehen müssen. was der Thatsache nicht entsprach.

Wen ich mich mm somit auf das negative Resultat meiner chemischen Analyse und die nachfolgenden Tersuclue stiitze, so muss ich mein Urtheil dahin zusammenfassen, dass, da eine Aufnahme bis zum Gleichgewicht jedenfalls nicht statfand, auch eine Aufwalme in leichterer. Weise ausgeschlossen war, denn sunst hätte sich in Laufe der Zeit das Gleichgewicht herstellen missen. Da aber somit das Kupfer nicht oder nur in Spureu in den Protoplasten eindringt, so ist wohl anzunelmmen. dass eben dadurch ganz wesentlich eine giftige Winkung remieden wird, welche grössere Mengen ron eindringendem gelösten Kupfer wahıscheinlich hervorrufen wiirden.

Ohnedies ist es schon nöthi⿺r, lass die Plasmalnant durch die mit ihı in Berührung stehende Kupfersulfatlösung nicht geschädigt wird. Denu andernfalls wïre ein Findringen des Kupfersalzes und lamit die Ternichtung des Lebens unvermeidlich, wie es ja in andern Ptianen') der Fall ist, dic aber ebenso wie dieser Schimmelpilz lelıen, dass der Finthuss subnaximaler Gittosen iberwindbas ist.

\section{Schlussfolgerungen.}

Die Ergebrisse meiner gesanmten Arlseit kann ich kurz dahir zusammentassen:

1. Die Concentrationsgrenzen für das ITachsthum der mntersuchten Schimmelpilze - Muror mucedo, asperyillus niger, Inotrylis

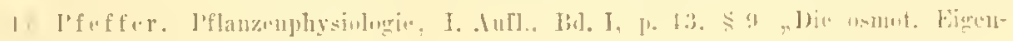

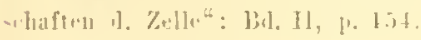


rineren und I'enicillinm yluremm - auf Metallgift enthaltenden Nährböden liegen je nach der Emptindlichkeit der Individıen für die ersten drei sehn tiet, tür I'enirillinm glonemm seln hoch.

2. Dic Einwirlung der einzelnen Metalle steht in Zusammenhange mit dem elektrolytischen Verlalten der betreffenden Lösung; und zwar ist sic abhängig von der phrsiologischen Wirkung des mudissociirten Theiles des Salzes und der betheiligten Mitwirkung des Kation.

3. Die Schimmelpilze sind in verschiedenem Grade accommodationstabing; in sehr hohem Maasse P'millium glaucum, wo schon das Individumm selbst ohne Wechsel der Generationen mit der Lïnge der Zeit einen holen Grad der Resistenz crwirbt.

4. In Folge dieser Accommodationsfähigkeit sind jene Wachsthumsgrenzen keine feststehenden, also keine unbedingten; vielmehr lassen sie sich durch allmähliche Anpassung erweitern, und zwar ist diese Erweiterung von der Anzahl der Generationen alslıängig.

5. Die günstigste Wirkung der Accommodation wird durch cine stufenweise, parallel zur Anzahl der Gonerationen erfolgende Steigerung des Metallgiftgehaltes erreicht.

6. $\mathrm{Ob}$ eine solche, durch Gewöhnung erworbene Eigenschaft zu einer danemden wird bezw. werden kamn, so dass man geneigt scin könnte, von einer Verorbung und einem bleibend veränderten Zustand der Art zu sprechen, liese Frage liess sich in dem zur Beobachtung benntaten Zeitrame nicht eruiren; nach den gemachten Erfahrungen aber muss man einer negativen Beantwortung zuneigen.

7. Das Kupfer wird ron Prnicillinm nicht oder wenigstens nicht in wesentlicher Menge aufgenommen, la für diesen Pilz eine Inpermeabilität der Plasmahaut gegenuiber diesem Metallsalze vorzuliegen scheint.

8. Die Anpassung des Pilzes und damit die Entwickehungsfihigkeit desselben auf einer solchen Metallgiftlösung wird so lange möglich sein, als die Plasmahaut durch die Beriilunng mit dem Giftstoff nicht geschädigt wird, wodurch die letale Dosis erreicht sein wiirde.

Torliegende Untersuchungen wuden in botanischen Institute dor Universitit Leipzig wiihend des Wintersemesters 1898,99 und 
ler heiden dariuf folirender Semester ausgeführt, und ich möchte es nicht rersïumen. anch an dieser Stelle meinem hochverehrten Lehrer, Herm Gehemrath Prof. Dr. IV. Pfeffer, für die freundliche Leitung und stete Förderung meiner studien meinen ehrerbietigsten Dank anszusprechen. -

\section{'Tabelle 1.}

Penicillium glaucum.

\begin{tabular}{|c|c|c|c|c|c|c|c|c|c|c|c|}
\hline \multirow{2}{*}{\multicolumn{2}{|c|}{ 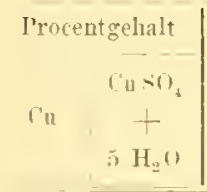 }} & \multirow{2}{*}{ 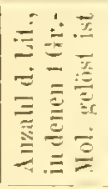 } & \multirow[b]{2}{*}{ 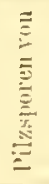 } & \multirow{2}{*}{\multicolumn{3}{|c|}{$\begin{array}{l}\text { Sichtbare } \\
\text { Keinmmg }\end{array}$}} & \multirow{2}{*}{\multicolumn{2}{|c|}{ II: be }} & \multirow{2}{*}{\multicolumn{3}{|c|}{ Fructilication }} \\
\hline & & & & & & & & & & & \\
\hline 11,003 & 11,0124 & 2000 & \multirow{8}{*}{ 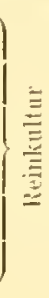 } & nach & $\because$ & Tagen & mach & 4 Tagen & nach & 5 & Tagen \\
\hline 11.03 & 0,124 & 200 & & • & $A$ & - & $\cdot r$ & $14 \quad$ & , & 21 & " \\
\hline 11,3 & 1.24 & 211 & & .. & 11 & n & •. & $21 \quad$ & $n$ & $\ddot{2}$ & Woniat \\
\hline 11.13 & -3.5 & 111 & & .. & $\because 1$ & $n$ & - & -2 M & $\cdot$ & 3 & $r$ \\
\hline 1.3 & 5 & $\tilde{j}$ & & " & $\because 1$ & ". & $\cdots$ & $\because \quad$ & n & : & , \\
\hline 3.2 & 12,5 & 2 & & $"$ & 11 & $n$ & $n$ & $2 \quad$ & " & 3 & . \\
\hline i...3 & $\because 5$ & 1 & & ". & & Monat & $"$ & $3-1$ & $"$ & 1 &. \\
\hline$\therefore, 3$ & $3: 3$ & 11.7511 & & $n$ & 4 & $r$ & $n$ & $\overline{5} \quad \pi$ & n & $\bar{\jmath}$ & .. \\
\hline
\end{tabular}

Aspergillus miger.

\begin{tabular}{|c|c|c|c|c|c|c|c|c|c|c|}
\hline$(1,1)(1)(1): 3$ & $(9,(1) 1) 1 \stackrel{1}{2} 4$ & 20111119 & $\Xi$ & nach & ¿ Taren & nath & \& Tagen & Matcl & ij & Tagers \\
\hline$(1.411) ; 3$ & (1). (1) 121 & 20010 & $\equiv$ & -. & j & , & 8 & , & 11 & $\Rightarrow$ \\
\hline$(1,, 0)+;$ & 11.0 .35 & 1000 & $\underline{\Xi}$ & & 11 & & & & & \\
\hline
\end{tabular}

Mreor mucedu.

\begin{tabular}{|c|c|c|c|c|c|c|c|c|c|c|}
\hline 11.1111113 & $11.11111=1$ & 21111111 & $\Xi$ & Matel| & 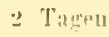 & |lile & 1 & 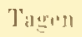 & $n+1 \cdot h$ & 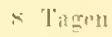 \\
\hline 1). 11163 & 11.11124 & $\Rightarrow 01040$ & $\overline{\bar{z}}$ & $\pi$ & $i$ & . & 111 & - & & 11 \\
\hline $11: 11116 ;$ & 11.11 .35 & 113110 & $\equiv$ & & 11 & & & & & \\
\hline
\end{tabular}

Botrytis cinereu.

\begin{tabular}{|c|c|c|c|c|c|c|c|c|c|c|}
\hline (1.111)(1); & 11,1111124 & 2011414 & 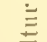 & uach & I 'l'a!" & nat:h & ; 'lagen & $\| a(c)]_{\|}$ & j & Tagen \\
\hline $11,110,3$ & 11.11124 & 2111113 & $\equiv$ & $\therefore$ & 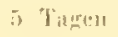 & .. & $s$ & ش & 11 & :. \\
\hline 11.11111; & 11.112 .5 & 1111111 & $\equiv$ & & 11 & & & & & \\
\hline
\end{tabular}




\section{Penicillim glancum.}

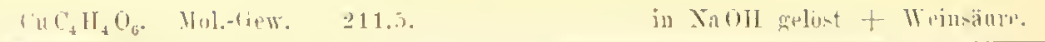

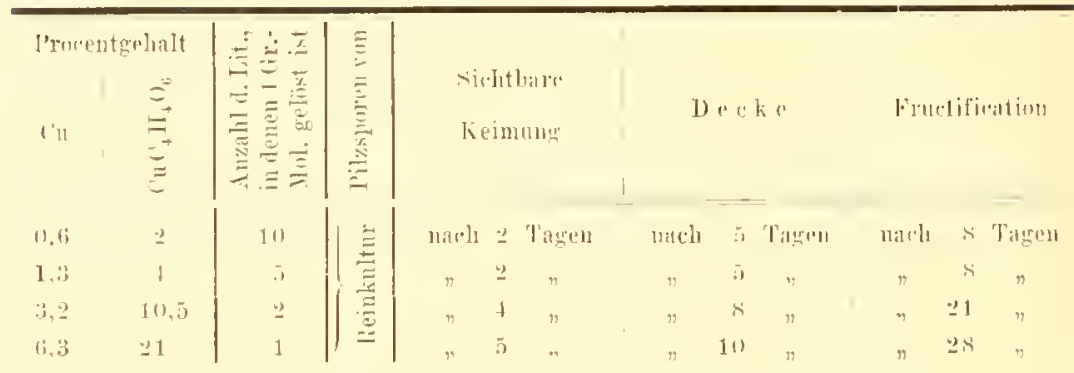

Aspergillus niger.

\begin{tabular}{|c|c|c|c|c|c|c|c|c|c|}
\hline 11,1$)(i$ & 11,2 & 11101 & $\equiv$ & liach & 1 Tar & nach & 3 Таgри & Mitull & $+\operatorname{Tag}^{2} \|$ \\
\hline $11.1 \%$ & 2 & 111 & E & $n$ & 3 Тацеи & 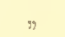 & j) & 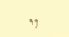 & $\bar{i}$ \\
\hline $1, \because 2$ & t & i & $\bar{E}$ & & 11 & & & & \\
\hline
\end{tabular}

Mucor muecto.

\begin{tabular}{|c|c|c|c|c|c|c|c|}
\hline $11,(101016$ & 11,112 & $1000+1$ & $\Xi$ & nach & $\Rightarrow$ Tacen & nacl 3 Tagen & nach ¿i Tagen \\
\hline $11,11.3$ & 11.1 & 2130 & $\stackrel{\bar{z}}{=}$ & $"$ & $1+$ & () & \\
\hline 11,$196 ;$ & 11,2 & 1110 & $\therefore$ & & 1) & & \\
\hline
\end{tabular}

Butrytis cinerea.

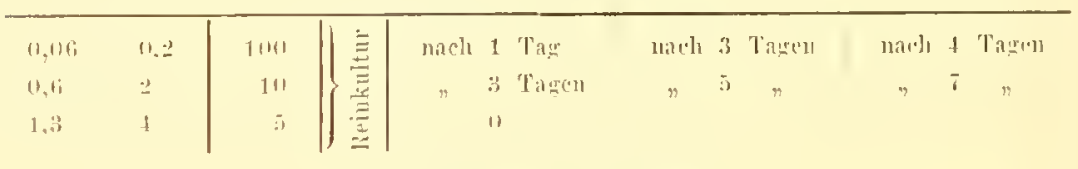

Penicilliem glonerum.

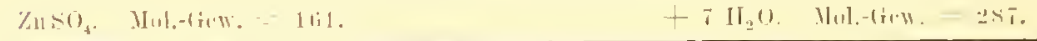

\begin{tabular}{|c|c|c|c|c|c|c|c|c|c|c|c|}
\hline \multicolumn{2}{|c|}{ 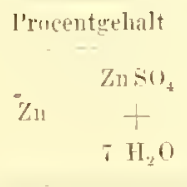 } & 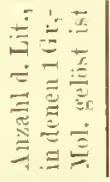 & 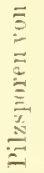 & \multicolumn{2}{|c|}{$\begin{array}{l}\text { sidelithaser } \\
\text { Livintuly }\end{array}$} & \multicolumn{3}{|c|}{ De l } & \multicolumn{3}{|c|}{ Fruetilicatiun } \\
\hline $11,00: 3$ & $0,118 \mathrm{i}$ & $20(111$ & & matrll & $=$ T"atgen & mat. $]_{l}$ & :" & Tạm & wath & 1 & Tagen \\
\hline $0,0: 2$ & $1,1 . j$ & 2011 & & $n$ & i & $"$ & $x$ & " & $n$ & 10 & $"$ \\
\hline 11,3 & $1, \pi$ & $=0$ & $\vdots$ & $r$ & $i$ & $"$ & 111 & " & $n$ & $1 \cdot 1$ & " \\
\hline $11,6.5$ & $\therefore \bar{T}$ & 111 & $\stackrel{\Xi}{\Xi}$ & $\because$ & $x$ & .. & $\because 1$ & " & “. & i & Worlt. \\
\hline $1,::$ & 5,7 & $i$ & $\bar{\Xi}$ & r & $s$ & $n$ & $\because 1$ & $"$ & $"$ & i & " \\
\hline$\therefore,-1$ & $14.3 . ;$ & $\because$ & $\cong$ & $n$ & s $\quad "$ & $*$ & 24 & $"$ & " & $i$ & $\because$ \\
\hline (i, is & $3 x .7$ & 1 & & $n$ & I Winhen & m & if & Hurle. & . & $i$ & .. \\
\hline$\therefore .7$ & is & $(1, \overline{7}(1)$ & & $"$ & $\simeq$ Ilıstat & $*$ & & Monat & , & $\ddot{3}$ & Monat \\
\hline
\end{tabular}


Aspergillas niger.

ZnaO). M[n.-Gew: = 161.

$+7 \mathrm{H}_{2} 0$. Mol.-(iew, $=287$.

\begin{tabular}{l}
\hline Trocentgehalt \\
\hline
\end{tabular}

Mucor mucedo.

\begin{tabular}{|c|c|c|c|c|c|c|c|c|c|}
\hline 11,017003 & 0,11015 & 2110001 & $\Xi$ & mach & $=$ Tagen & nach & 4 Tagen & thach & \& Tagen \\
\hline 17,0113 & 0,1115 & 2000 & 㭉 & . & $\bar{\pi}$ & $"$ & 10 & & 11 \\
\hline 17,0617 & 11.113 & $1+11011$ & $\underset{\Xi}{\Xi}$ & & (1) & & & & \\
\hline
\end{tabular}

Botrytis cinerea.

\begin{tabular}{|c|c|c|c|c|c|c|c|c|c|c|c|}
\hline 11.141103 & $0,001+15$ & 211000 & $\vdots$ & mach & 1 Tag & nach & 3 & Tagen & nackl & 3 & Tagen \\
\hline 11,1161;3 & $11,111.5$ & 2000 & $\equiv$ & $r$ & 3 T"ingen & $"$ & $j$ & $"$ & $"$ & $x$ & $n$ \\
\hline 11,113 & 11,15 & 2001 & $\equiv$ & $"$ & $\therefore$ & $"$ & 14 & $"$ & $n$ & $\because 1$ & .. \\
\hline 0,117 & $(1,3$ & 100 & & & $(1$ & & & & & & \\
\hline
\end{tabular}

\section{Penieillium glaneum.}

Xist. Mol, Hew. $=154,7$.

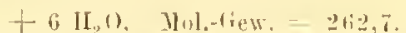

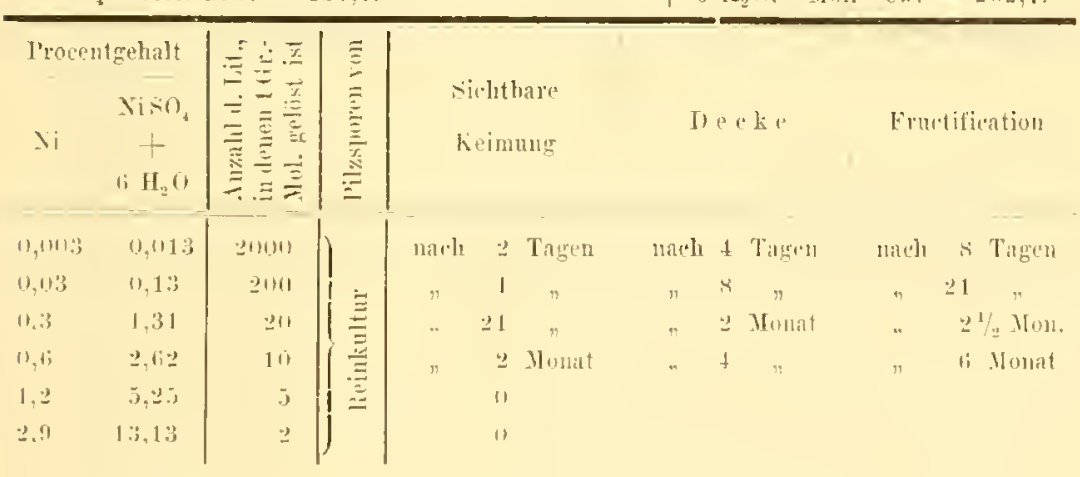

Aspergillus niger.

\begin{tabular}{|c|c|c|c|c|c|c|c|c|c|c|c|}
\hline$(1,111111,3$ & $(1,0012)$ & $2(1)(11)$ & $\Xi$ & Marll & $\geq \mathrm{T}_{\mathrm{d}} \mathrm{s}_{5}$ & llaclt & 1 & Tageril & 11:14 & $x$ & 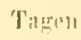 \\
\hline $0.1311: 3$ & $11,111: 3$ & 2111,1 & $\underline{\Xi}$ & $n$ & 8 & . & 111 & $*$ & 11 & 21 & . \\
\hline 11,$11111 ;$ & 11.11234 & $111111)$ & $\equiv$ & & 11 & & & & & & \\
\hline
\end{tabular}


Mucor mencero.

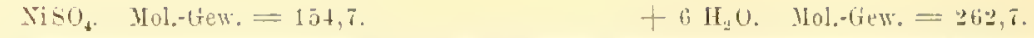

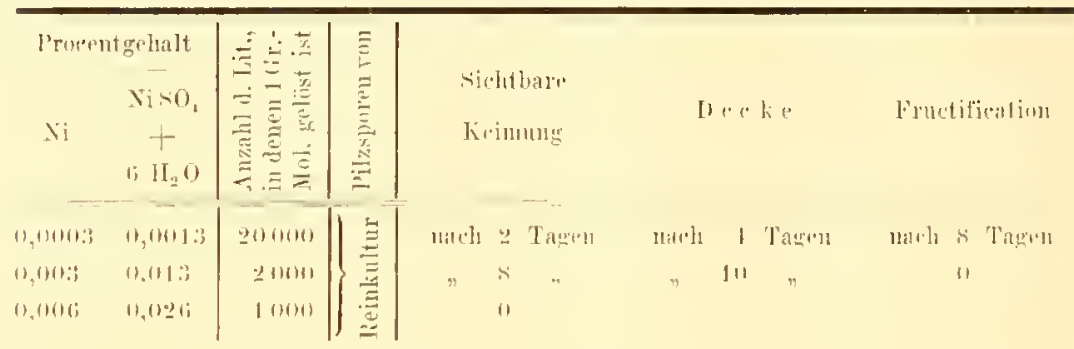

Botintis cinerea.

\begin{tabular}{|c|c|c|c|c|c|c|c|c|c|c|c|}
\hline 11.1000 .3 & $11,0111: 3$ & $=11000$ & $\leqq$ & r!nth & $\Rightarrow$ Та & matult & 1 & 'T'agen & nacls & li & Tag*.ı \\
\hline 0.003 & $\{1,0113$ & 2000 & 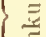 & .. & 5 & $r$ & 111 & " & . & 14 & $*$ \\
\hline$(1,006$ & 0,026 & 1000 & 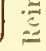 & & 0 & & & & & & \\
\hline
\end{tabular}

\section{Penicillium ylanemur.}

Mnso. Mol.-(iew. $=151$.

$+5 \mathrm{H}_{2} 0$. Mol-diew. $=2 \downarrow 1$.

\begin{tabular}{|c|c|c|c|c|c|c|}
\hline \multicolumn{2}{|c|}{ I'muntgehalt } & 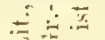 & $\widetilde{\Xi}$ & & & \\
\hline$\| 11$ & $\begin{array}{c}\text { (In } \rightarrow)_{4} \\
+ \\
\therefore \mathrm{H}_{2} \mathrm{O}\end{array}$ & 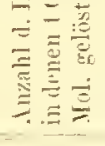 & 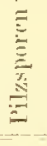 & $\begin{array}{l}\text { siehthare } \\
\text { Kinum }\end{array}$ & ll $10 k$. & Pructifiantiun \\
\hline$(1,11: 1,1$ & $(1,2+1$ & $2(1) 1)$ & & & & \\
\hline$(1, \bar{i}+\vdots)$ & 2.4 & 111 & & narb 1 'litg' & nich is Tagern & \\
\hline 1.1 & 4..4 & .7 & $\underline{E}$ & & & mach $x$ Tayen \\
\hline $27 x$ & 12 & ' & $\underline{3}$ & match + Titeren & & \\
\hline $\bar{x}, 45$ & $\because 1$ & 1 & $\underline{E}$ & $+\quad r$ & mach \& Tagen! & \\
\hline 7.28 & $: 32$ & $11,7: 31\}$ & & $n \quad i \quad n$ & & \\
\hline $1: 3.4 \mathrm{i}$ & (ill & $(1.1000$ & & $n 111 \quad n$ & niald $1 \vec{i}$ Tiagell & 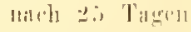 \\
\hline
\end{tabular}

\section{Prnicillimm glaucom.}

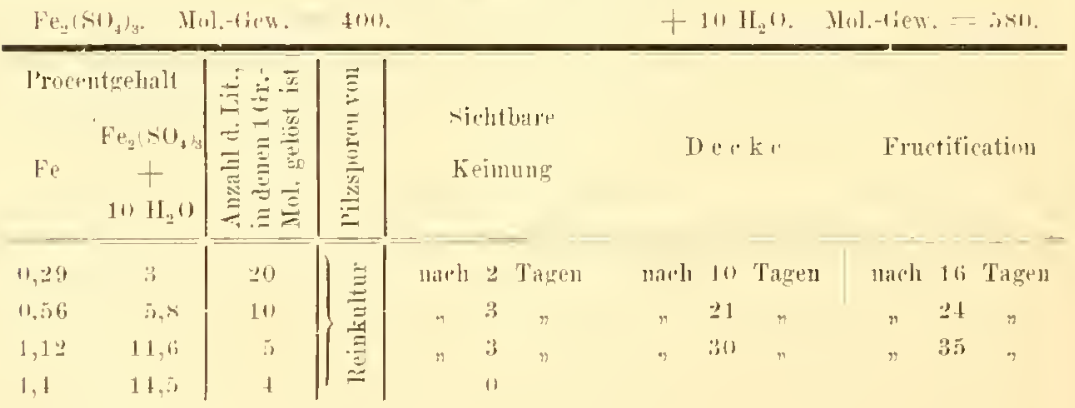




\section{Penicillium glaucum.}

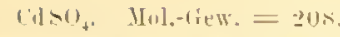

$+11_{2}()$. Hol.-1iew $=2$ siti.

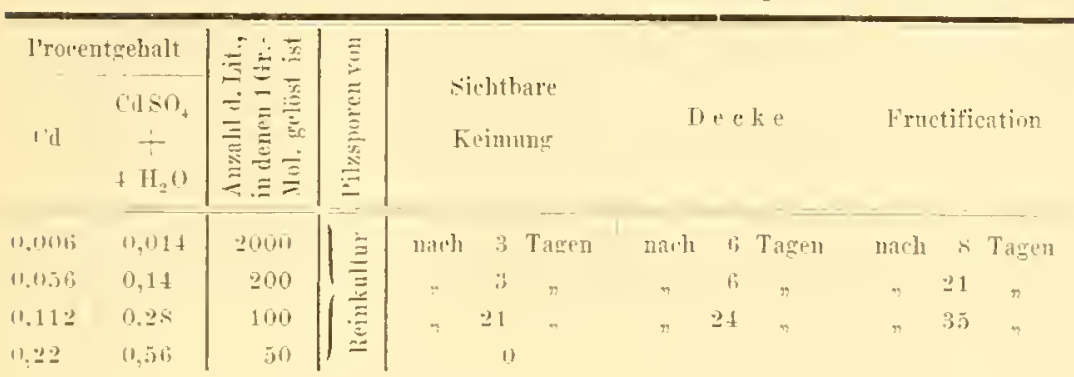

\section{Penicillim glaweum.}

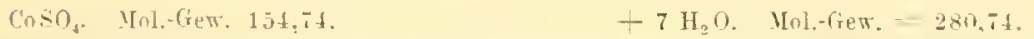

\begin{tabular}{|c|c|c|c|c|c|c|c|c|c|c|c|}
\hline \multicolumn{2}{|c|}{ Procentgehalt } & $=-\bar{x}$ & $\cong$ & \multirow{2}{*}{\multicolumn{2}{|c|}{$\begin{array}{l}\text { Sichthare } \\
\text { Keimung }\end{array}$}} & \multirow{2}{*}{\multicolumn{3}{|c|}{ Itpeke }} & \multirow{2}{*}{\multicolumn{3}{|c|}{ Fructifieation }} \\
\hline 1.1 & $\begin{array}{c}\text { (os). } \\
+ \\
711.0\end{array}$ & 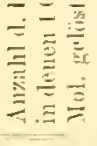 & 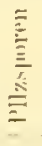 & & & & & & & & \\
\hline$(1.1)(1.3$ & 0,014 & 2000 & 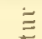 & wateh & $\because \mathrm{Tagen}$ & wach & 3 & $\operatorname{Teg} p^{2} n$ & nath h & \pm & Tagen \\
\hline 0,$0 ; 3$ & 0.14 & 21111 & 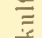 & - & 3 & :. & $i$ & $n$ & $"$ & $\bar{i}$ & . \\
\hline 11,010 & $11,2,4$ & $1(16)$ & $\stackrel{\Xi}{\bar{E}}$ & n & j & $\sim$ & 21 & . & - & $y$ & " \\
\hline 11.12 & $11,36 i$ &.$j 0$ & $\approx$ & & 11 & & & & & & \\
\hline
\end{tabular}

\section{Pericillinm gloucum.}

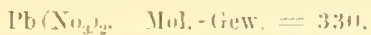

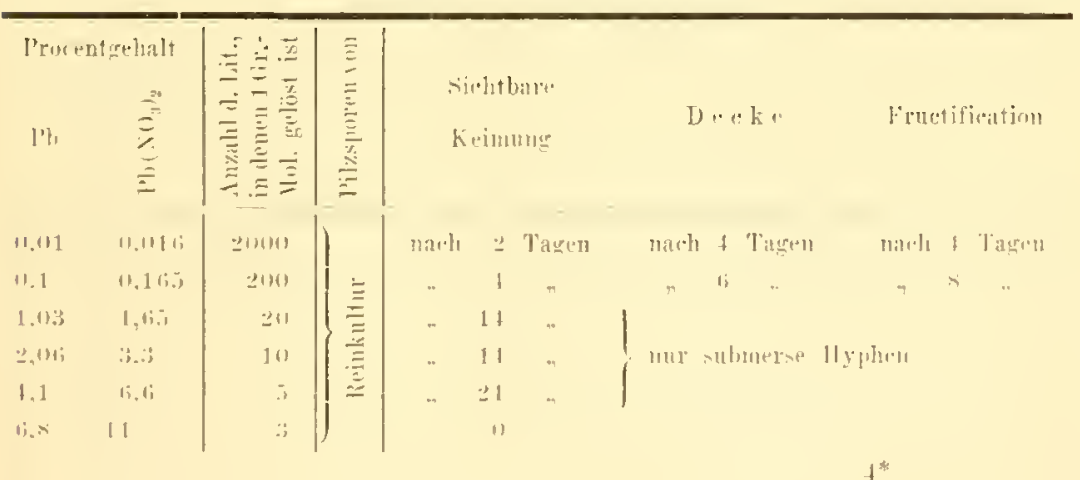




\section{Penicillium ylaucum.}

Th.sos. M[n],-Gaw. $=504$.

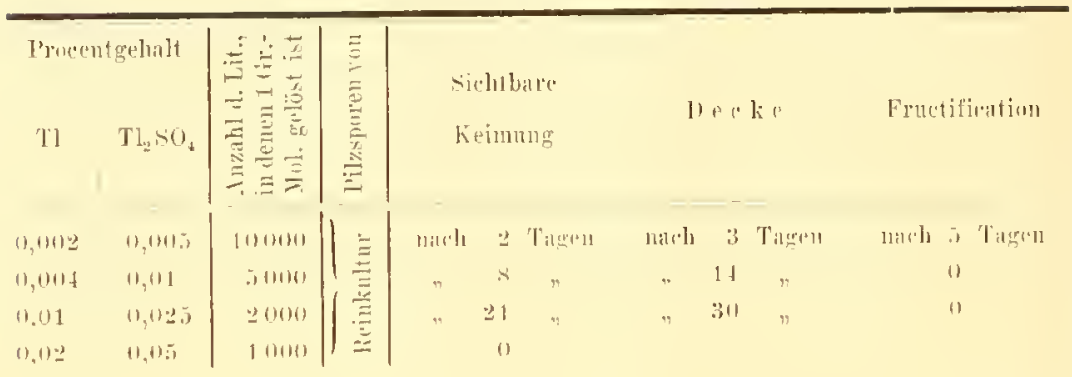

\section{I'enicillimm glancum.}

IL

\begin{tabular}{|c|c|c|c|c|c|c|c|c|c|c|c|c|}
\hline \multicolumn{2}{|c|}{ Irocentgelnalt } & 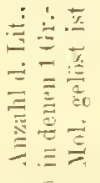 & 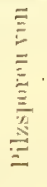 & & & & \multicolumn{3}{|c|}{ D a cku } & \multicolumn{3}{|c|}{ Frnctitiontion } \\
\hline 0,001 & $0,01011 \geq 0 ;$ & 20000 & & nated & 1 & Tag & nach & $::$ & Tagen & nach & 4 & Tagen \\
\hline 0,002 & 0,0025 & $100(010)$ & $\Xi$ & $n$ & 1 & $"$ & $"$ & $t$ & $"$ & $"$ & $T$ & $"$ \\
\hline$(1,111$ & $11,01 \geq 1$ & $\geqslant 10+11$ & 三 & $\pi$ & & Taren & $"$ & $1+$ & n & $"$ & $11 i$ & " \\
\hline 10,112 & 11,1125 & 1000 & 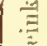 & $"$ & :3 & $"$ & $"$ & 21 & $n$ & $"$ & 28 & $"$ \\
\hline 10,114 & 0,115 & $5(10)$ & $\approx$ & $"$ & 14 & y & $"$ & 25 & $n$ & $n$ & $\because x$ & $n$ \\
\hline (1), 1 & $11.1 \geq 15$ & 2170 & & & () & & & & & & & \\
\hline
\end{tabular}

\section{I'enicillimm glancum.}

IIgl.. Mul.trew. $=271$.

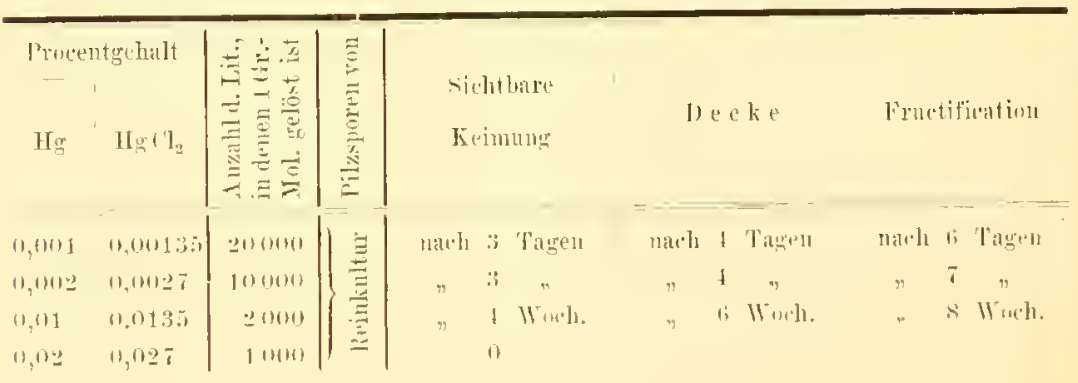


Tabelle II.

Penicillicum glaucum.

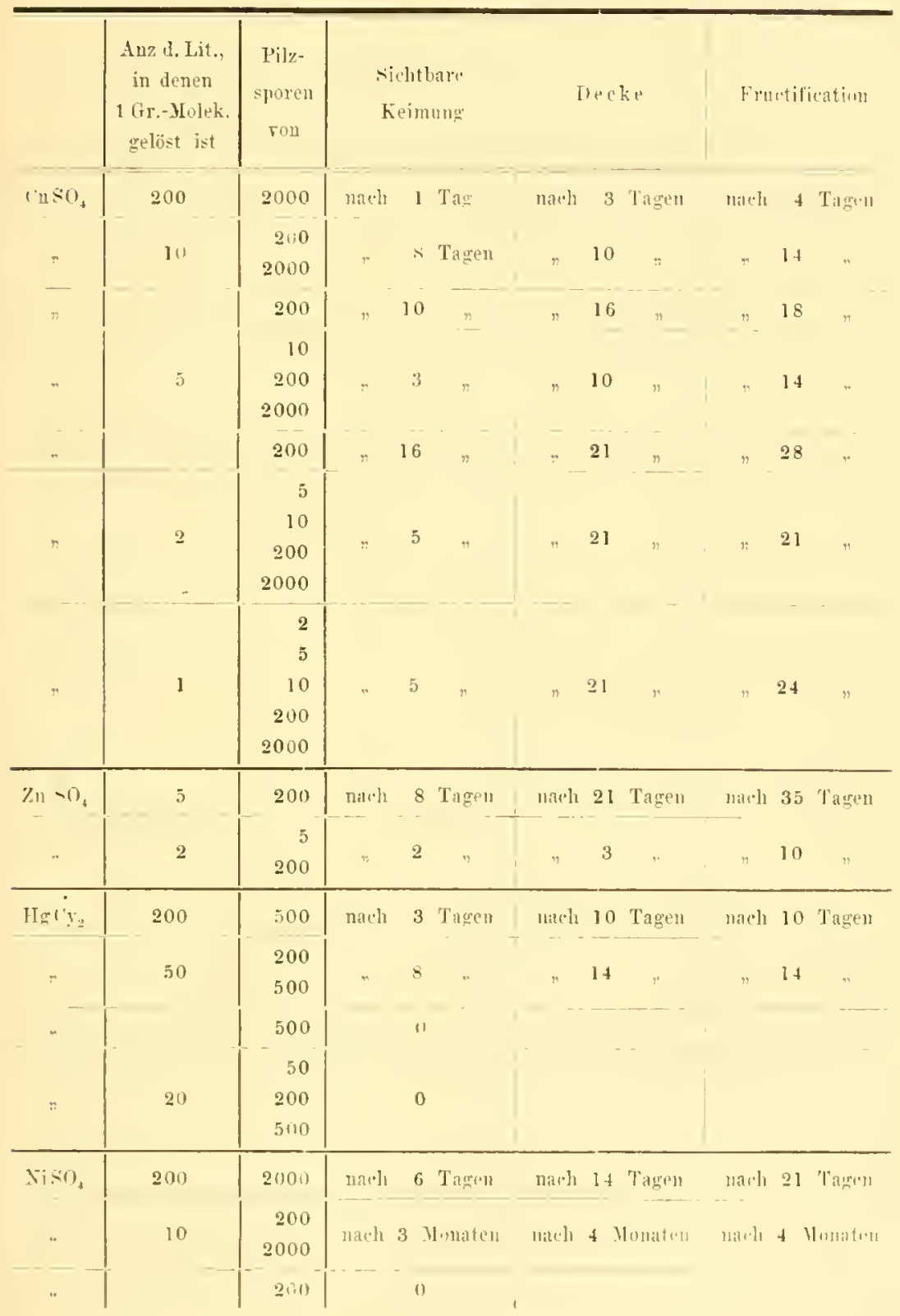


I'enicillium glancum.

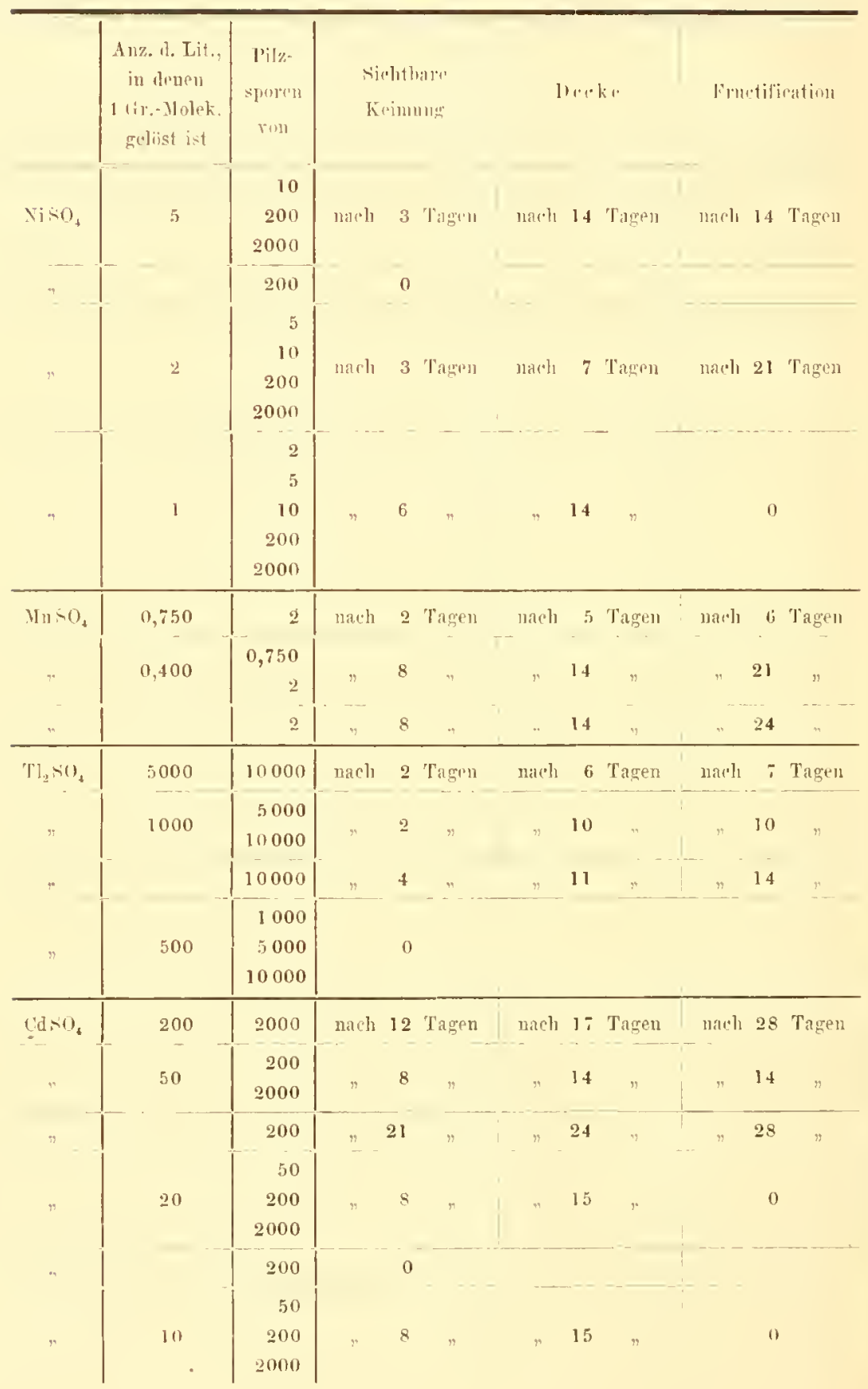




\section{Penicillium glancum.}

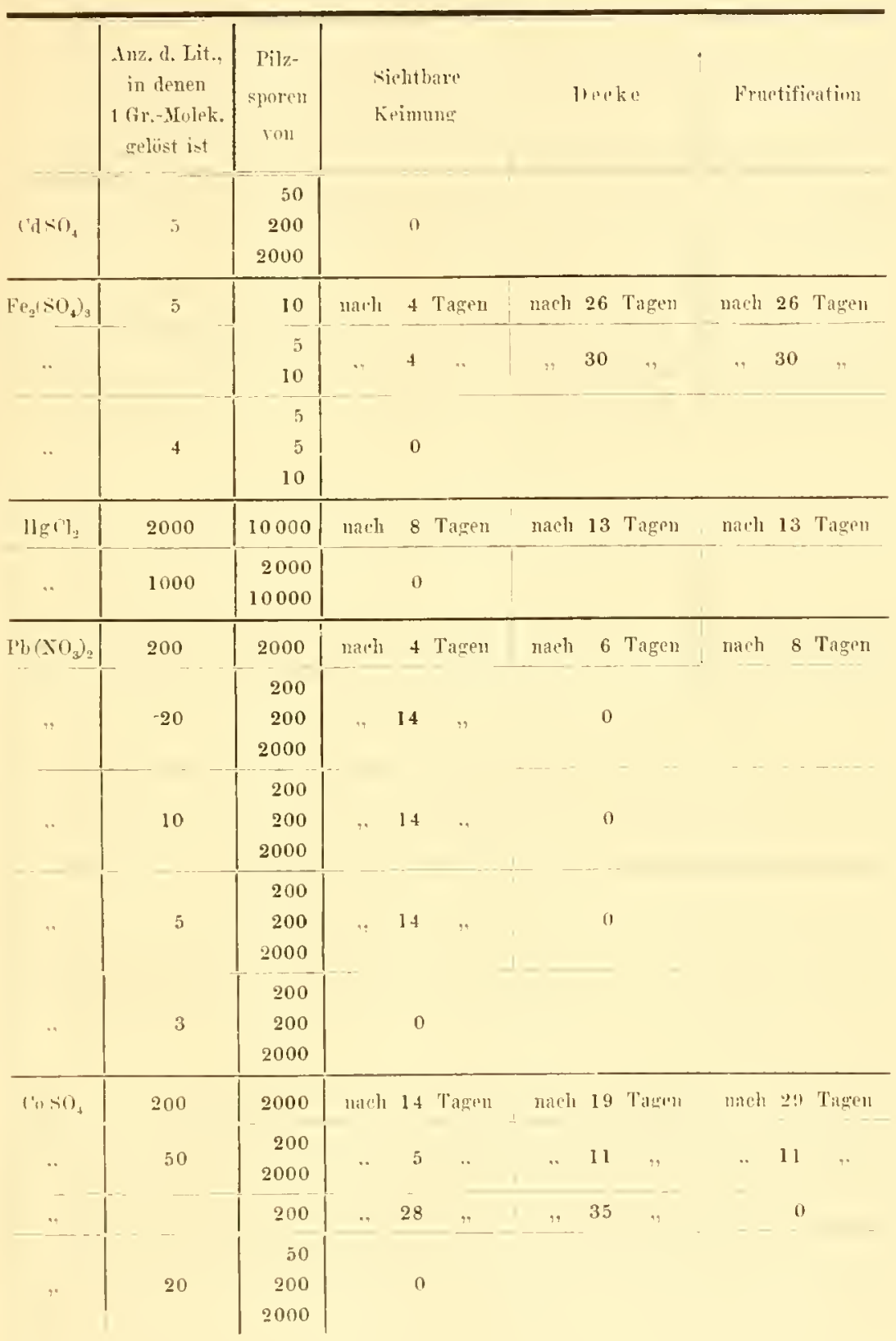


Tabelle III.

Penicillium ylaucum.

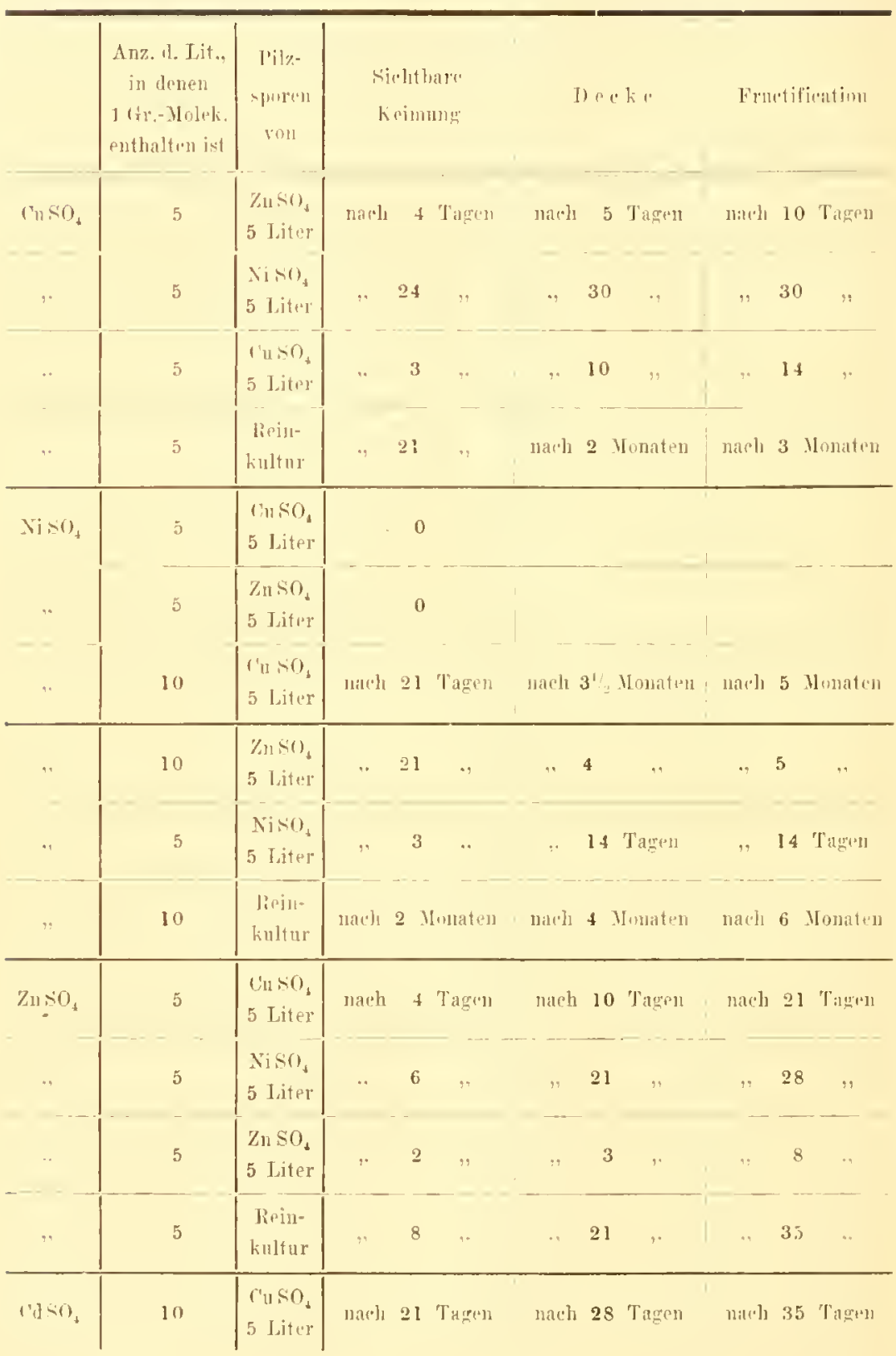


Penicillium glaucum.

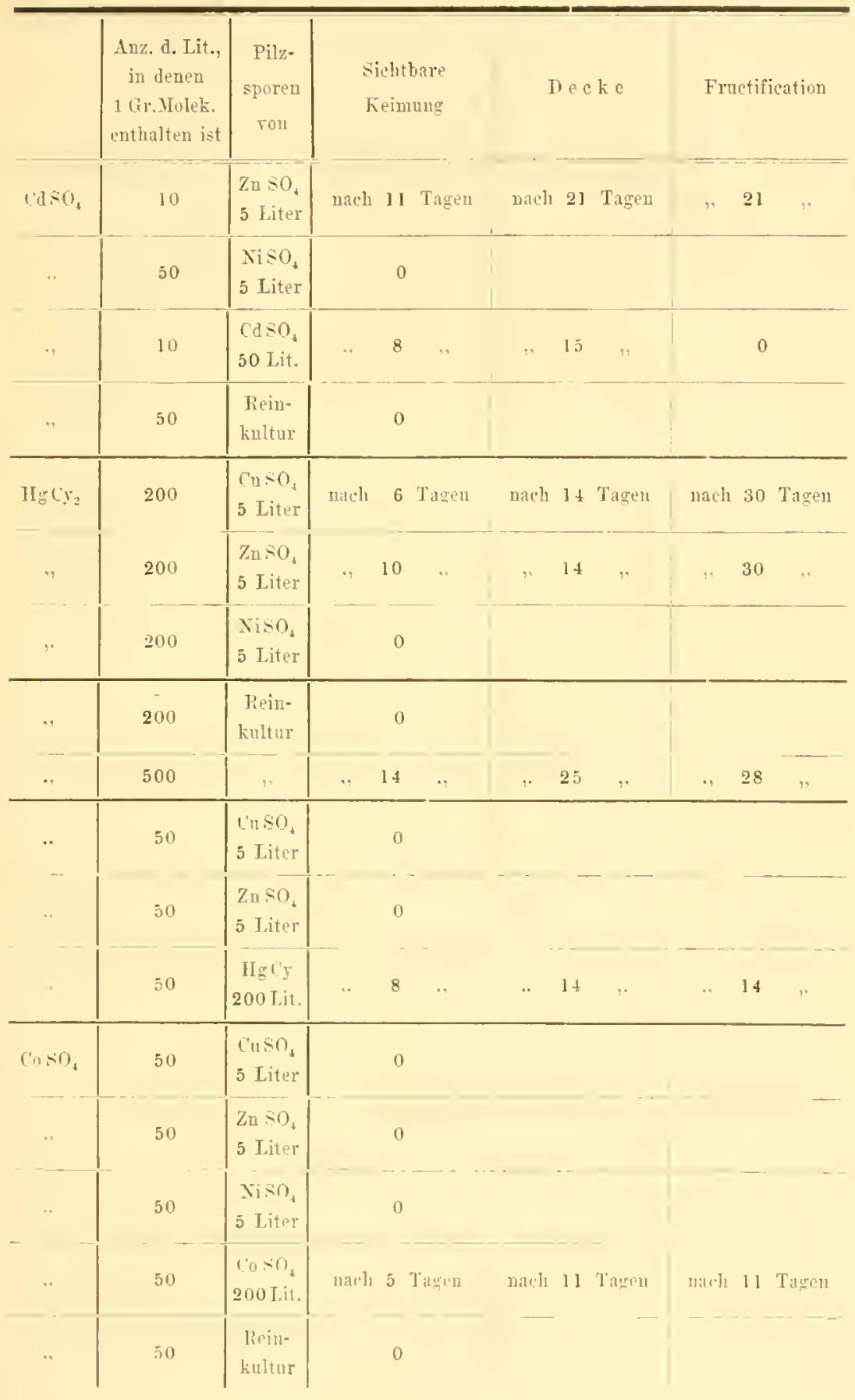


Tabelle IV.

I'emicillinm glonemur.

\begin{tabular}{|c|c|c|c|c|c|c|c|c|c|c|c|}
\hline & 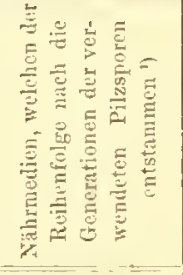 & 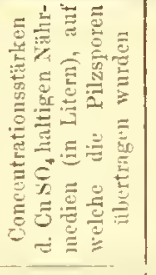 & & chetbi & & & 1,10 & ]i 1. & 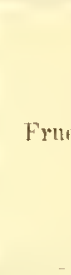 & etifir & ation \\
\hline 1 & $\begin{array}{l}200 \text { Liter } \\
\text { Reinkultur }\end{array}$ & $\begin{array}{c}5 \\
(\text { isot. }- \text { Lit.) }\end{array}$ & marh & 14 & Tagim & mach & 21 & Tagen & nacels & 28 & Tagen \\
\hline 2 & $-\begin{array}{cc}200 & \text { Litn } \mathrm{r} \\
200 & n \\
200 & n \\
200 & n \\
200 & n\end{array}$ & $\frac{5}{(\text { isot. } 2 \text { Lit.) }}$ & ,. & 3 & $"$ &. & 21 & *. & .4 & 21 & .. \\
\hline 3 & $=\begin{array}{r}10 \\
200\end{array}$ & $\begin{array}{c}5 \\
\text { (isot. 2 I it.) }\end{array}$ & $\cdot$, & 2 & 19 & ", & 10 & $"$ & ", & 21 & " \\
\hline 4 & $\begin{array}{rr}5 & " \\
10 & . " \\
200 & "\end{array}$ & $\begin{array}{c}5 \\
\text { (isot. } 2 \text { Lit.) }\end{array}$ & 9 & 2 & 19 & 9 & 4 & $"$ & " & 21 & ." \\
\hline 5 & $\begin{array}{l}200 \text { Liter } \\
\text { Reinkulter }\end{array}$ & 2 & $"$ & 8 & $n$ & $"$ & 21 & $n$ & , & 25 & ", \\
\hline 6 & $\rightarrow \mid \begin{array}{cc}200 & \text { Iiter } \\
200 & " \\
200 & " \\
200 & " \\
200 & "\end{array}$ & 2 & . & 5 & " & " & 21 & $"$ & $"$ & 21 & 9 \\
\hline 7 & $\Xi \mid \begin{array}{rr}5 & " \\
200 & ",\end{array}$ & 2 &.. & 2 & •" & $"$ & 10 & " & $:$ & 21 & ". \\
\hline 8 & $\begin{array}{rr}2 & 9 \\
5 & \eta \\
200 & \text { " }\end{array}$ & 2 & , & 2 & " & ", & 5 & 19 & i1 & 21 & " \\
\hline
\end{tabular}

1) Sanmtliche Fulturen sind isotonisch \& Lites. 
Tabelle V.

Penicillinm glalu:mm.

I.

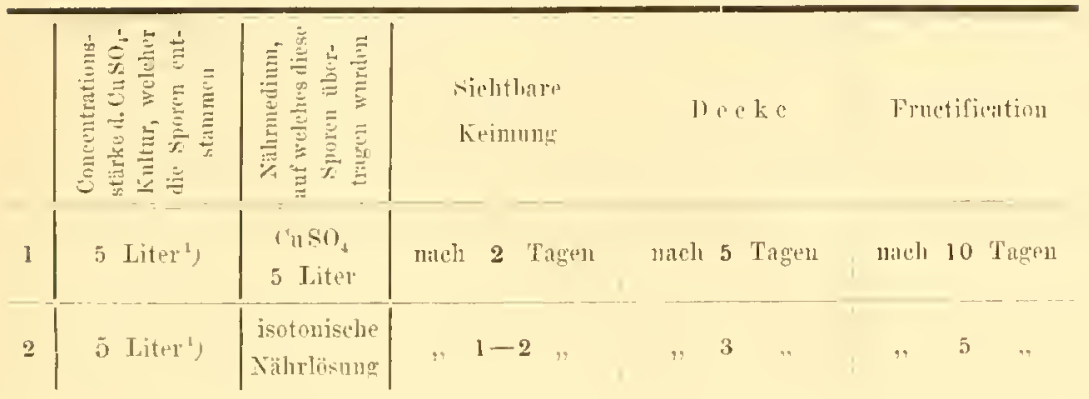

I3.

\begin{tabular}{|c|c|c|c|c|c|c|c|}
\hline & 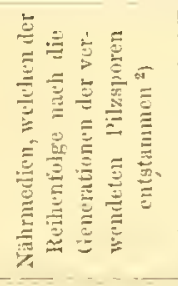 & 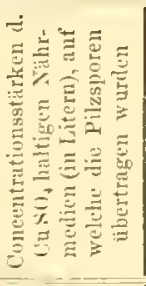 & \multicolumn{3}{|c|}{$\begin{array}{l}\text { Fichthare } \\
\text { Keimung }\end{array}$} & Decke & .. \\
\hline 1 & Reinkultur & 5 & mach & 21 & Tagen & naclı 2 Moniter & makh 3 Vumaten \\
\hline 2 & $\begin{array}{c}\text { Reinkultur } \\
\text { CuSO, } 5 \text { Liter }\end{array}$ & 5 & $n$ & 10 & $n$ & naㄴ 21 'Tagen & math 24 Tagen \\
\hline 3 & $\begin{array}{l}\text { Reinkultur } \\
\text { Reinkultux } \\
\text { ' 'u } \mathrm{SO}_{4} 5 \text { Liter' }\end{array}$ & 5 & $"$ & 14 & $"$ & " 30 & $" 40$ \\
\hline 4 & $\begin{array}{l}\text { Reinkultur } \\
\text { Reinkultur } \\
\text { Reinkultur } \\
\text { Cuso, } 5 \text { I,iter }\end{array}$ & 5 & " & 20 & r & minc] 2 Wonaten & 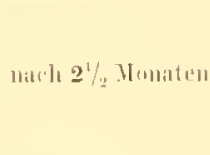 \\
\hline
\end{tabular}

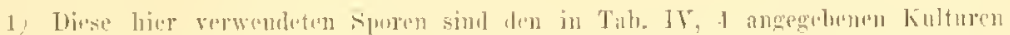

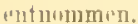

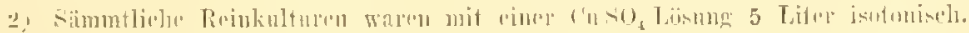






